\title{
Y-box binding protein 1 regulates liver lipid metabolism by regulating the Wnt/B-catenin signaling pathway
}

\author{
Zhenzeng Ma, Yu Zhu, Qizhi Wang, Min Deng, Jianchao Wang, Dapeng Li, Lin Gu, Rui Zhao, \\ Shanjun Yan \\ Department of Gastroenterology, The First Affiliated Hospital of Bengbu Medical College, Bengbu, China \\ Contributions: (I) Conception and design: Z Ma, M Deng; (II) Administrative support: None; (III) Provision of study materials or patients: Y Zhu, D \\ Li; (IV) Collection and assembly of data: Q Wang, J Wang; (V) Data analysis and interpretation: L Gu, R Zhao, S Yan; (VI) Manuscript writing: All \\ authors; (VII) Final approval of manuscript: All authors. \\ Correspondence to: Shanjun Yan; Yu Zhu. Department of Gastroenterology, The First Affiliated Hospital of Bengbu Medical College, No. 287 \\ Changhuai Road, Bengbu 233004, China. Email: Yansj2006@163.com; 294968638@qq.com.
}

Background: We mainly investigated how y-box binding protein $1(Y B-1)$ regulates liver lipid metabolism through the $\mathrm{Wnt} / \beta$-catenin signaling pathway using multiple models.

Methods: The LO2 cells were treated with palmitic acid (PA) to create an NAFLD model in vitro. Immunohistochemistry and Western blotting assays were used to detect the expression of $Y B-1, \beta$-Catenin, SREBP-1c, LXRa, FXR1 and PPAR $\alpha$ protein, and RNAs of them was detected by qRT-PCR. Oil Red O assay was applied to observe lipid droplets in LO2 cells and liver tissues. H\&E staining was performed to observe the degree of liver inflammation. Proteomics in LO2 cells were conducted by Tandem mass tag proteomics assay. Co-immunoprecipitation and Western blotting assays were used to verify $Y B-1$ complexed pGSK3 $\beta$. ELISA and Western blotting assays were used to detect the concentrations of TNF $\alpha$ and IL-6 in supernates of LO2 cells and liver tissues, respectively.

Results: We found that $Y B-1$ and $\beta$-catenin were highly expressed in the LO2 cell NAFLD model, and that the expression of TNF $\alpha$ and IL-6 also increased. Lipid synthases (SREBP-1c and $L X R a$ ) expression were decreased, while $\beta$-oxidation-related factors (FXR1 and PPAR $\alpha$ ) expression were increased. The expression of SREBP-1c and $L X R a$ were increased while FXR1 and PPAR $\alpha$ were decreased, though such responses were rescued through inhibiting $\beta$-catenin expression. Finally, tandem mass tag proteomics, coimmunoprecipitation, and Western blotting demonstrated that $Y B-1$ could form a protein complex with phosphorylated glycogen synthase kinase 3 beta $(\mathrm{pGSK} 3 \beta)$ to regulate $W n t / \beta$-catenin. In mouse NAFLD livers, immunohistochemistry and Western blotting validated the finding of $Y B-1$ gene downregulation leading to the inhibition of $\mathrm{Wnt} / \beta$-catenin pathway activation, ultimately inhibiting lipid synthesis and reducing the inflammatory response. Similar to the in vitro investigation, $\beta$-catenin overexpression reversed such $Y B-1$ downregulation-induced downstream effects. Upregulation of the $Y B-1$ gene promoted the activation of the $\mathrm{Wnt} / \beta$-catenin pathway, thus increasing lipid synthesis and the inflammatory response. However, downregulation of $\beta$-catenin reversed this phenomenon caused by upregulating $Y B-1$.

Conclusions: In summary, these results demonstrate that $Y B-1$ regulates liver lipid metabolism by regulating the $\mathrm{Wnt} / \beta$-catenin signaling pathway.

Keywords: Y-box binding protein 1 (YB-1); non-alcoholic fatty liver disease (NAFLD); Wnt/ $\beta$-catenin signaling; lipid metabolism; inflammatory response

Submitted Oct 08, 2021. Accepted for publication Nov 17, 2021.

doi: 10.21037/atm-21-5767

View this article at: https://dx.doi.org/10.21037/atm-21-5767 


\section{Introduction}

Non-alcoholic fatty liver disease (NAFLD) has emerged as the most prevalent condition that contributes to chronic hepatic ailments worldwide, and consists of a heterogeneous spectrum of diseases including simple steatosis, steatohepatitis, advanced fibrosis, and cirrhosis $(1,2)$. Specifically, non-alcoholic steatohepatitis (NASH) can progress to liver cirrhosis and primary liver cancer, becoming the main cause of liver-related morbidity and mortality $(3,4)$. Although the prevalence of NAFLD is closely associated with obesity, type 2 diabetes mellitus (T2DM), and insulin resistance, However, these researches mainly focus on the etiology, epidemiology and progression of lipid metabolism in NAFLD and the pathogenic mechanism of NAFLD is still poorly understood (5-7). The aim of this study is to investigate the molecular mechanism of NAFLD.

Y-box binding protein $1(Y B-1)$, as a member of the family of DNA/RNA-binding proteins, can regulate gene expression in the cytoplasm and the nucleus. Generally, $Y B-1$ is recruited to mRNAs in the cytoplasm or it can bind to Y-box elements (CCAAT-box) in the promoter regions of some genes in the nucleus, thereby regulating their translation and transcription $(8,9)$. Recently, an investigation demonstrated that $Y B-1$ is involved in the progression of fatty acid synthesis (10). However, there is currently minimal research focused on the role of $Y B-1$ in NAFLD pathogenic mechanisms.

Recently, some investigations have shown that Wnt/ $\beta$-catenin signaling plays a pivotal role in liver inflammation and liver fibrosis development, together with chronic liver injury progression (11-13). In addition, some studies demonstrated that the $\mathrm{Wnt} / \beta$-catenin signaling pathway can regulate lipid metabolism in the liver $(14,15)$. We present the following article in accordance with the ARRIVE reporting checklist (available at https://dx.doi.org/10.21037/ atm-21-5767).

\section{Methods}

\section{Animals and the NAFLD mouse model}

Thirty-five-day-old C57BL/6 mice were procured through Sino-British Sippr/BK Laboratory. Under specific pathogen-free conditions, they were housed at a constant temperature $\left(22 \pm 2{ }^{\circ} \mathrm{C}\right)$ and $60 \%$ relative humidity, with 12:12-h light-dark cycle in the Animal Experimental Center of Bengbu Medical College (Bengbu, China). All the animal procedures were performed in accordance with the Guidelines for the Care and Use of Laboratory Animals of Bengbu Medical College and were approved by the Animal Ethics Committee of Bengbu Medical College (Bengbu, China) under a project license (No. 2021-096). Wild type C57BL/6 mice were divided into a normal diet group and a high-fat diet group (HFD—comprising 60\% fat-derived calories) (BioServ ${ }^{\mathrm{TM}}$, Frenchtown, NJ, USA). The mice in the HFD group were fed in this manner for an uninterrupted timespan of 12 weeks. Meanwhile, the normal diet group was treated with a healthy balanced dietary intake (Keaoxieli ${ }^{\mathrm{TM}}$, Beijing, China).

\section{Cell culture and establishment of the NAFLD model}

LO2 hepatocytes were used in this study. The cell cultures were expanded in Dulbecco's modified Eagle's medium (DMEM) (Thermo Fisher ${ }^{\mathrm{TM}}$, USA), supplemented with $10 \%$ fetal bovine serum (Thermo Fisher ${ }^{\mathrm{TM}}$, USA), $100 \mathrm{U} /$ $\mathrm{mL}$ penicillin, and $100 \mu \mathrm{g} / \mathrm{mL}$ streptomycin. For steatosis induction, the cells were treated with $0.4 \mathrm{mM}$ palmitic acid (PA) to create an NAFLD model in vitro. The culture medium and PA were replaced every $24 \mathrm{~h}$ for $72 \mathrm{~h}$.

\section{Construction of YB-1 lentiviruses and $\beta$-catenin plasmid}

A lentiviral vector LV-3 carrying a green fluorescent protein (GFP) reporter (GenePharma, Shanghai, China) was employed for expressing short hairpin RNA (shRNA) that targeted the $Y B-1$ sequence (5'-GCCTAGAGAGGATGGCAATGA-3'), and an additional lentiviral vector LV-5/GFP reporter delivery system was employed for overexpressing RNA that targeted the $Y B-1$ sequence (ID: 22608, NM_011732.2), with LV3 and LV5 (vector) as the control. pGMLV-SC5 RNAi carrying a GFP reporter (Genomeditech ${ }^{\mathrm{TM}}$, Shanghai, China) was employed for expressing shRNA that targeted $\beta$-catenin (5'-GCACCATGCAGAATACAAATG-3'), with PGMLV-6395 (vector) serving as the control plasmid. A PGMLV-6395/GFP reporter delivery system was employed for overexpressing RNA that targeted $\beta$-catenin (CTCGAGGCCACCGGATCC).

In brief, $\mathrm{LO} 2$ cells in medium were transfected using $\operatorname{sh} Y B-1, \operatorname{sh} \beta$-catenin, overexpressed $Y B-1$, overexpressed $\beta$-catenin, and its corresponding vector with Lipofectamine $3000^{\circledR}$ (Invitrogen ${ }^{\mathrm{TM}}$, Carlsbad, CA) as per the manufacturer's protocol. After an incubation period of $72 \mathrm{~h}$, transcriptomic/proteomic quantitative LO2 cell 
Table 1 Antibodies for Western blotting (WB), co-immunoprecipitation (Co-IP), and immunohistochemistry (IH)

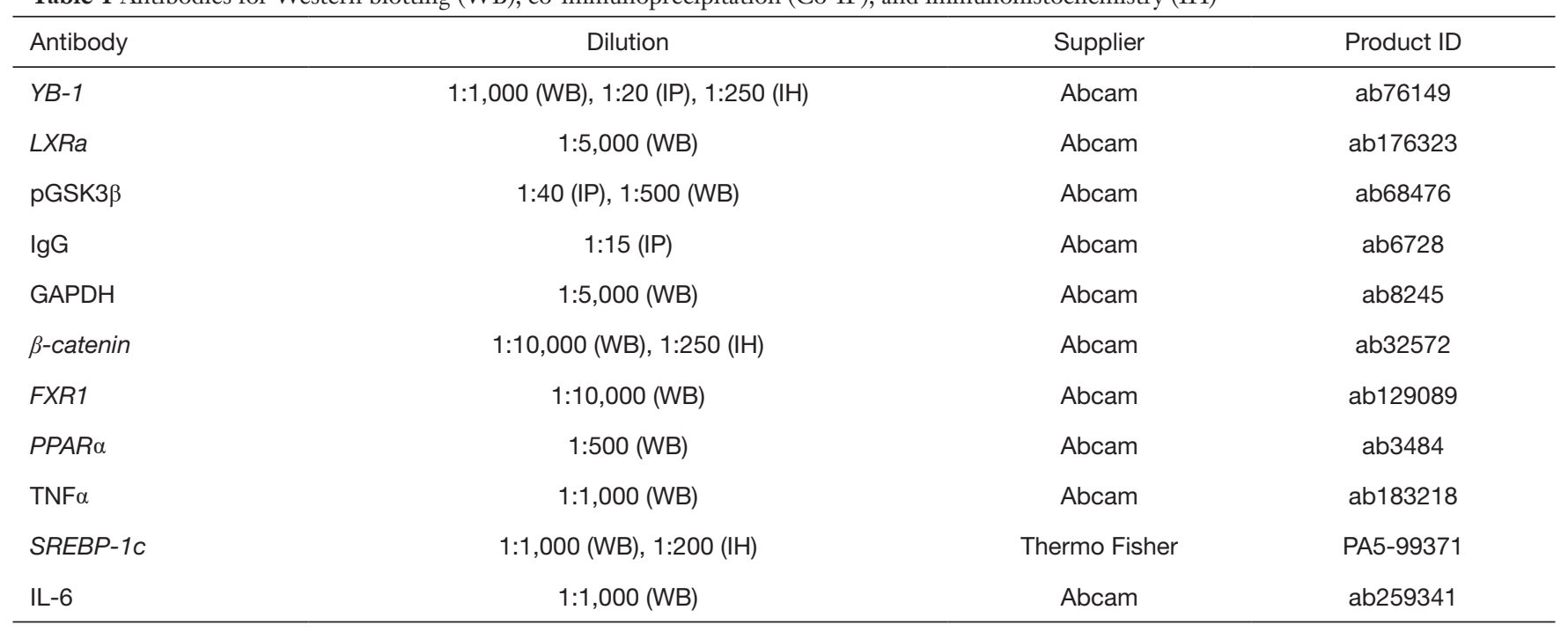

YB-1, y-box binding protein 1; LXRa, Liver X Receptor $\alpha$; pGSK3 $\beta$, phosphorylation glycogen synthase kinase 3 beta; IgG, immunoglobulin G; GAPDH, reduced glyceraldehyde-phosphate dehydrogenase; FXR1, farnesoid X receptor1; PPAR $\alpha$, peroxisome proliferator-activated receptor-alpha; TNF $\alpha$, tumor necrosis factor $\alpha$, SREBP-1C, sterol regulatory element binding protein-1c; IL-6, interleukin 6 .

analyses, from all experimental arms, were conducted using qRT-PCR and Western blotting.

\section{Immunobistochemistry (IH)}

For the IH process, formalin-fixed paraffin-embedded liver samples were cut into $4 \mu \mathrm{m}$ sections, then deparaffinized and rehydrated. Antigen retrieval was performed using sodium citrate $(20 \mathrm{~min})$. Samples were then incubated in $3 \% \mathrm{H}_{2} \mathrm{O}_{2}(15 \mathrm{~min})$, pretreated by boiling in $10 \mathrm{mM}$ sodium citrate buffer ( $\mathrm{pH}$ 6.0) (20 min), and then washed 3 times with phosphate-buffered saline (PBS). Blocking was performed in $5 \%$ bovine serum albumin (BSA) for $0.5 \mathrm{~h}$ at room temperature. The primary antibodies in $1 \%$ BSA were incubated overnight at $4{ }^{\circ} \mathrm{C}$ in a humid chamber. After horseradish peroxidase-conjugated secondary antibody incubation for $0.5 \mathrm{~h}$ at room temperature, the specimens were counter-stained using 4',6-diamidino-2-phenylindole (DAPI). Staining of each liver tissue sample was repeated 3 times. Lastly, the Barnes method was employed as the immune scoring system. Details of the primary/secondary antibodies are listed in Table 1.

\section{Hematoxylin and eosin (H\&E) and Oil Red O staining}

$H \& E$ staining was performed to observe the degree of liver inflammation. Formalin-fixed paraffin-embedded liver samples were cut into $3 \mu \mathrm{m}$ sections and stained with $\mathrm{H} \& \mathrm{E}$ (Beyotime $^{\mathrm{TM}}$, China), followed by light microscopy-based visualization. In addition, hepatic cryosections were stained using an Oil Red O kit (Sigma, USA) and counter-stained using hematoxylin in order to observe lipid droplets under light microscopy.

\section{Quantitative Real-time PCR (qRT-PCR)}

Total RNA was extracted from liver tissues using TRIzol $^{\mathrm{TM}}$ reagent (Thermo Fisher, USA) and then reverse transcribed into cDNA using Hieff ${ }^{\mathrm{TM}}$ First Strand cDNA Synthesis Super Mix for qRT-PCR (Yeasen, China). Hieff qPCR SYBR Green Master Mix ${ }^{\circledR}$ (Applied Biosystems ${ }^{\mathrm{TM}}$, CA, USA) together with Hieff First Strand cDNA Synthesis Super Mix for qRT-PCR ${ }^{\circledR}$ (Applied Biosystems ${ }^{\mathrm{TM}}$ ) were employed for qPCR. All experiments were repeated 3 separate times. GAPDH served as a normalization/reference gene. Primer sequences are illustrated in Table 2.

\section{Western blotting (WB) assay}

Total protein was extracted with RIPA lysis buffer (Thermo Fisher, USA). Equivalent protein sample quantities $(70 \mu \mathrm{g})$ were separated through $10 \%$ SDS-PAGE and then transferred onto PVDF membranes $(0.22 \mu \mathrm{m})$. Subsequently, membranes were blocked using $5 \%$ skimmed 
Table 2 Primer sequences for RT-PCR analysis

\begin{tabular}{lcc}
\hline Target & Forward primer & Reverse primer \\
\hline YB-1 & TAGACGCTATCCACGTCGTAG & ATCCCTCGTTCTTTCCCCAC \\
SREBP-1C & ACAGTGACTTCCCTGGCCTAT & GCATGGACGGGTACATCTTCAA \\
LXRa & ACACCTACATGCGTCGCAAG & GACGAGCTTCTCGATCATGCC \\
FXR1 & CTGCGACAGATTGGTTCTAGG & TGTACCATAACCGGAGGTGTAA \\
PPAR $\alpha$ & TTCGCAATCCATCGGCGAG & CCACAGGATAAGTCACCGAGG \\
$\beta$-catenin & AGCTTCCAGACACGCTATCAT & CGGTACAACGAGCTGTTTCTAC \\
\hline
\end{tabular}

$Y B-1$, y-box binding protein 1; SREBP-1c, sterol regulatory element binding protein-1c; LXRa, Liver X Receptor $\alpha$; FXR1, farnesoid X receptor1; $P P A R \alpha$, peroxisome proliferator-activated receptor-alpha.

milk $+0.1 \%$ Tris Buffered Saline Tween (TBST) for $1 \mathrm{~h}$ at room temperature, followed by incubation with primary antibodies at $4{ }^{\circ} \mathrm{C}$ overnight. Membranes were washed 3 times with TBST and then incubated with the corresponding secondary antibody for $1 \mathrm{~h}$ at room temperature. Bands were identified through the enhanced chemiluminescence (ECL) (Thermo Fisher, USA) system, followed by X-ray radiation (LAS MINI $4000^{\circledR}$, Japan). The protein expression levels of individual bands were assessed through ImageJ (National Institute of Health, Bethesda, MD, USA). Each assay was performed in triplicate across individual experiments. GAPDH served as a normalization protein for protein expression assessments. Details of primary antibodies are listed in Table 1.

\section{Tandem mass tag proteomics}

SDT pyrolysis methods were used to extract proteins for proteomics, and the bicinchoninic acid (BCA) kit (Pierce ${ }^{\mathrm{TM}}$ BCA, Thermo Fisher, USA) was used to test sample concentrations. The loading buffer (6x) was added to $20 \mu \mathrm{g}$ protein samples, which were then boiled for 5 min, separated by $12 \%$ SDS-PAGE, and stained by Coomassie bright blue. Enzymatic hydrolysis was then performed through FASP, tagged by TMT, and separated through High PH RP. Subsequently, mass spectrometry was performed using the Easy nLC system and mass spectrum identification was performed by Q Exactive. Using Blast2 Gene Ontology (GO) to annotate the target protein, the process consisted of sequence alignment (blast), GO item extraction (mapping), GO annotation (annotation), and supplementary annotation augmentation. Kyoto Encyclopedia of Genes and Genomes (KEGG) pathway analysis was performed through KOALA (KEGG
Orthology And Links Annotation), and enrichment analysis of GO/KEGG annotations was performed by Fisher's exact test. Protein cluster analysis was performed using matplotlib software.

\section{Co-immunoprecipitation (Co-IP)}

Pierce Co-IP kits (Thermo Fisher, USA) were applied to extract total protein from $\mathrm{LO} 2$ cells, and the protein levels were evaluated using a BCA protein quantification kit (Thermo Fisher, USA). The experiment was conducted according to the Pierce Co-IP kit guidelines. In brief, pre-cleared lysate was set using control agarose resin. Subsequently, immobilized anti- $Y B-1(20 \mu \mathrm{g} / \mathrm{mg}$ lysate $)$ and anti-pGSK3 $\beta$ (40 $\mu \mathrm{g} / \mathrm{mg}$ lysate), together with control IgG antibodies ( $20 \mu \mathrm{g} / \mathrm{mg}$ lysate), were introduced into the amino link/coupling resin solution. A $400 \mu \mathrm{g}$ sample of precleared lysate was incubated with various immobilization antibodies at $4{ }^{\circ} \mathrm{C}$ for $12 \mathrm{~h}$ and then the mixture was washed with $60 \mu \mathrm{L}$ of elution buffer. All immune precipitates were boiled for $10 \mathrm{~min}$ and evaluated through a WB assay. Details of the primary antibodies are illustrated in Table 1.

\section{Enzyme-linked immunosorbent assay (ELISA)}

The supernatants of non-steatosis and steatosis LO2 cells grown in 12-well plates were harvested on day 3 and frozen at $-20{ }^{\circ} \mathrm{C}$ until assay. A quantitative ELISA kit for TNF $\alpha$ (Murine TNF- $\alpha$ ELISA Kit, PeproTech, USA, BGK06804) was used to detect the concentration of TNF $\alpha$ in supernatants according to the manufacturer's protocol. A quantitative ELISA kit for IL-6 (IL-6 Mouse ELISA Kit, Thermo Fisher, USA, BMS603-2) was used to detect the concentration of IL-6 in supernatants, as per 
the manufacturer's protocol. A histogram of the TNF $\alpha$ and IL-6 concentration was created using GraphPad Prism ${ }^{\circledR}$ (GraphPad Software Inc. ${ }^{\mathrm{TM}}$, USA, version 8.0).

\section{Statistical analysis}

Data were presented as mean \pm SE. All statistical analyses were conducted through SPSS $20.0^{\circledR}$ software (IBM ${ }^{\mathrm{TM}}$ SPSS; Armonk, NY, USA). Two-way ANOVA was applied to interpret the differences between treatment groups. $\mathrm{P}<0.05$ indicated a statistically significant result.

\section{Results}

The expression levels of $Y B-1$ and $\beta$-catenin were higher in NAFLD liver tissues

After mice were fed with a HFD or normal diet for 12 weeks continuously, the liver samples were collected and used in experiments. Lipid deposits were increased in NAFLD liver tissues compared with normal liver tissues (Figure 1A). The degree of inflammatory response was more serious compared to that of normal liver tissues (Figure 1B). Subsequently, we found that the expression of $Y B-1$ protein was higher in the NAFLD group (Figure 1C,1D). Furthermore, qRT-PCR/WB indicated that $Y B-1 \mathrm{mRNA}$ and protein expression was upregulated in the NAFLD group (Figure $1 E-1 G$ ). Interestingly, we found that the protein and gene expression of $\beta$-catenin was also higher in the NAFLD group (Figure $1 \mathrm{H}-1 \mathrm{f}$ ). At the same time, the expression levels of TNF $\alpha$ and IL-6 were higher in the NAFLD group compared with the normal liver group (Figure $1 K, 1 L$ ).

\section{The expression levels of $Y B-1$ and $\beta$-catenin were increased in the LO2 cell NAFLD model in vitro}

To further explore the correlation between $Y B-1$ and $\beta$-catenin in hepatocyte steatosis, we established an LO2 cell NAFLD model in vitro through cultured LO2 cells in DMEM induced by PA (Figure 2A). We found that the expression levels of genes and proteins related to lipid synthesis (SREBP-1c and $L X R a)$ were higher in steatosis LO2 cells, but the expression levels of genes and proteins related to $\beta$-oxidation (FXR1 and $P P A R \alpha$ ) were lower (Figure 2B-2D). Furthermore, we also found that the gene and protein expression levels of $Y B-1$ and $\beta$-catenin were elevated in steatosis LO2 cells (Figure $2 E-2 G$ ). Finally, the inflammation factors TNF $\alpha$ and IL-6 were also increased in steatosis LO2 cells (Figure 2H,2I).

\section{$Y B-1$ regulated lipid synthesis and the expression of $\beta$-catenin in LO2 cells}

In order to investigate the effect of $Y B-1$ on LO2 cell lipid synthesis and the expression of $\beta$-catenin, a $Y B-1$ lentivirus was constructed to regulate the gene and protein expression levels of $Y B-1$. Subsequently, non-steatosis and steatosis LO2 cells were transfected with the $Y B-1$ lentivirus and its corresponding vector, and the RNA and protein were collected for experiments at the indicated time. First, we confirmed that $\operatorname{sh} Y B-1$ lentivirus could effectively inhibit and overexpression $Y B-1$ lentivirus could effectively increase the gene and protein expression levels of $Y B-1$ (Figure $3 A, 3 B$ ). Second, in steatosis LO2 cells, we demonstrated that downregulation of $Y B-1$ inhibited lipid synthesis, but upregulation of $Y B-1$ promoted lipid synthesis (Figure 3C). Furthermore, we found that downregulation of $Y B-1$ inhibited the expression of $S R E B P-1 c$ and $L X R a$ mRNA, but increased the expression of FXR1 and PPAR $\alpha$ mRNA. However, upregulation of $Y B-1$ promoted the expression of SREBP-1c and $L X R a$ mRNA, but inhibited the expression of FXR1 and PPAR $\alpha$ mRNA (Figure 3D-3G). Third, the WB assay showed that the protein expression levels of $S R E B P-1 c, L X R a$, $F X R 1$, and PPAR $\alpha$ were consistent with their mRNA expression levels. At the same time, we also found that downregulation of $Y B-1$ inhibited the expression level of $\beta$-catenin protein, but upregulation of $Y B-1$ increased the expression level of $\beta$-catenin protein (Figure 3H,3I). Finally, the results showed that inhibited lipid synthesis by $\operatorname{sh} Y B$ 1 downregulated the contents of TNF $\alpha$ and IL- 6 in the corresponding supernatant, but increased lipid synthesis induced by overexpression of $Y B-1$ upregulated the contents of TNF $\alpha$ and IL-6 (Figure 37,3K).

\section{$Y B-1$ combined with $p G S K 3 \beta$ to regulate the expression of $\beta$-catenin in LO2 cells}

In order to examine the molecular mechanisms of $Y B-1$ in regulating $\beta$-catenin levels in LO2 cells, we conducted a tandem mass tag proteomics assay. LO2 cells were transfected with shYB-1 lentivirus and cultured in DMEM + PA for $72 \mathrm{~h}$, and then total protein was extracted for experiments. The results showed that a total of 300 proteins were upregulated and 376 proteins were 

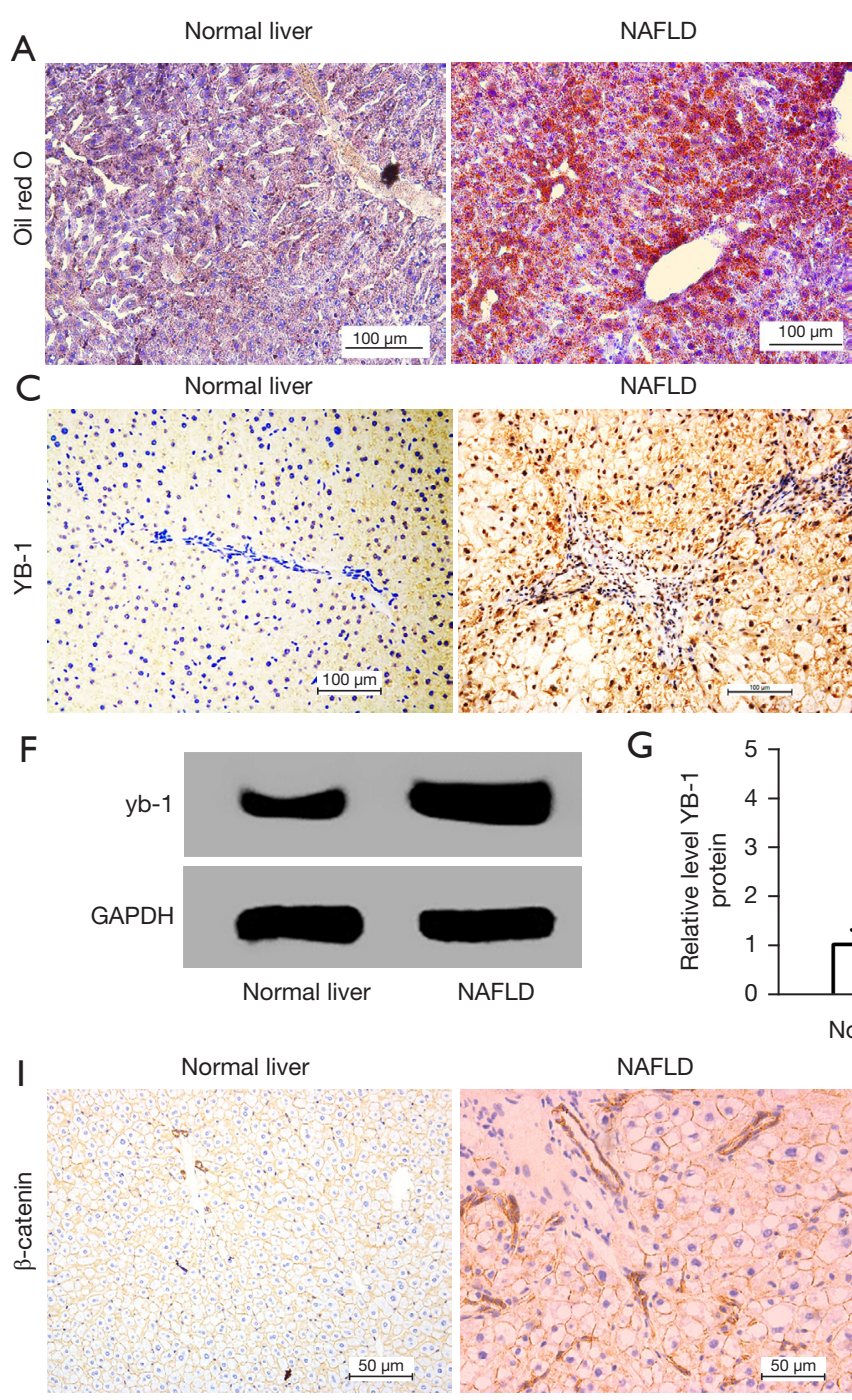

K

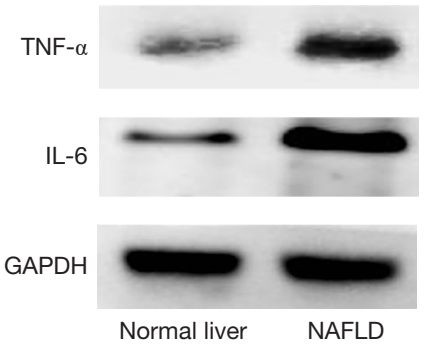

NAFLD

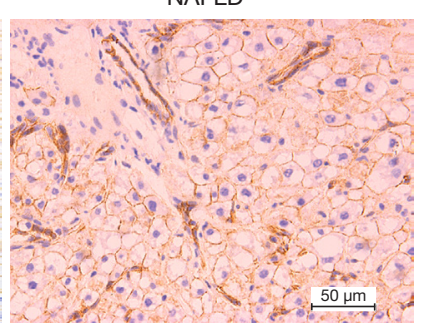

$\mathrm{L}$
NAFLD

NAFLD
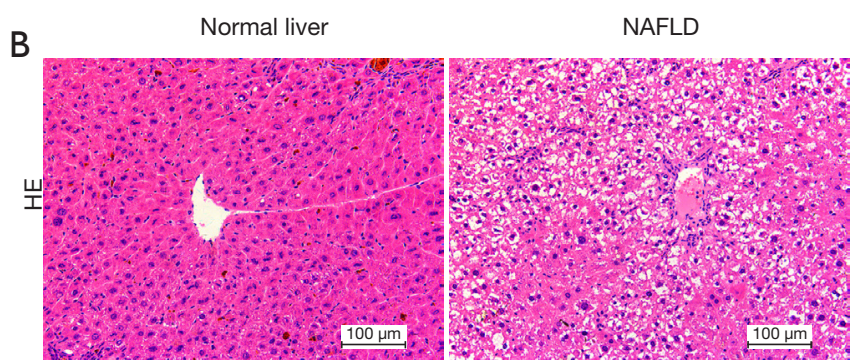

D

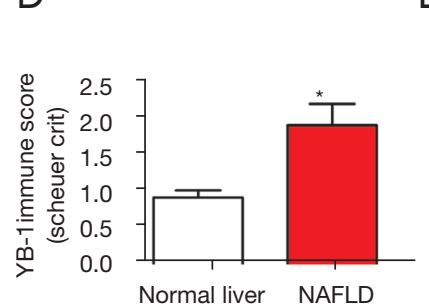

E

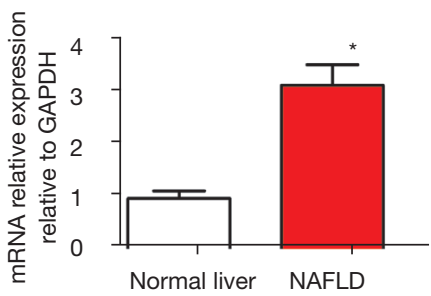

G

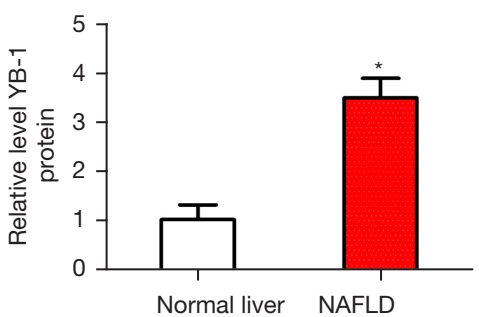

$\mathrm{H}$

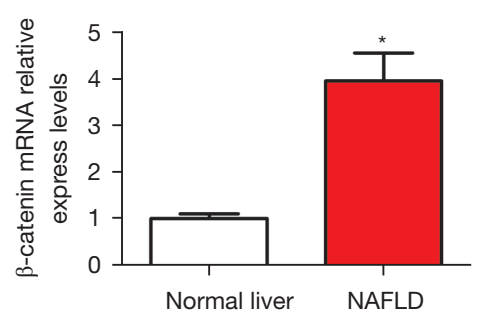

\section{J}
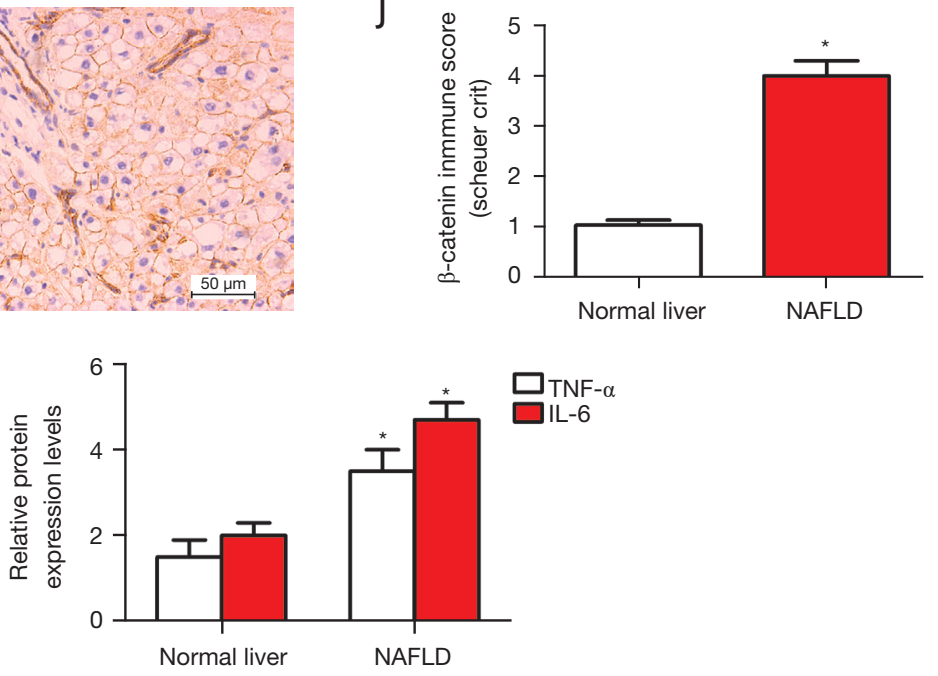

Figure 1 The expression levels of $Y B-1$ and $\beta$-catenin were elevated in liver samples of mouse NAFLD livers. (A) Oil Red O staining showing lipid deposits (scale bar $=100 \mu \mathrm{m}, \mathrm{n}=20$ per group); (B) H\&E staining indicating the degree of inflammation and steatosis in liver tissues (scale bar $=100 \mu \mathrm{m}, \mathrm{n}=20$ per group); (C,D) immunohistochemical staining and histogram presenting quantification of the immune score for $Y B-1$ in the above liver tissue (scale bar $=100 \mu \mathrm{m}, \mathrm{n}=20$ per group; * $\mathrm{P}<0.05$ compared with the normal liver group, $\mathrm{n}=3$ per experiment); (E-G) the gene and protein expression levels of $Y B-1$ in the above groups $\left(^{*}, \mathrm{P}<0.05\right.$ compared with the normal liver group, $\mathrm{n}=3$ per experiment); $(\mathrm{H})$ the gene expression levels of $\beta$-catenin in the above groups $\left(^{*}, \mathrm{P}<0.05\right.$ compared with the normal liver group, $\mathrm{n}=3$ per experiment); ( $\left.\mathrm{I}, \mathrm{J}\right)$ immunohistochemical staining and histogram presenting quantification of the immune score for $\beta$-catenin in the above liver tissues (scale bar $=50 \mu \mathrm{m}, \mathrm{n}=20$ per group); (K,L) WB assays demonstrated the expression of TNF $\alpha$ and IL-6 in the above groups ( ${ }^{*}$, P<0.05 compared with the normal liver group, $\mathrm{n}=3$ per experiment). NAFLD, Non-alcoholic fatty liver disease; $Y B-1, \mathrm{y}$-box binding protein 1 ; WB, Western blot. 
A

A

$\circ$
0
$\stackrel{0}{\underline{D}}$
$\overline{0}$

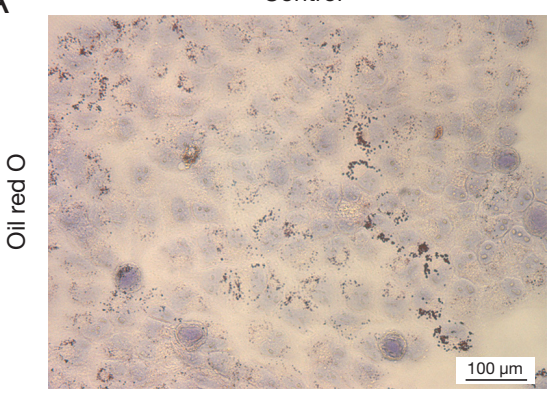

Control

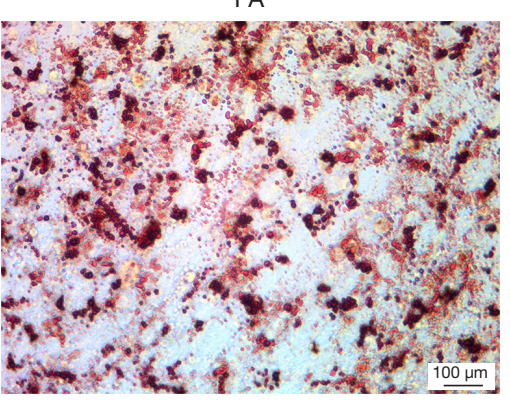

B

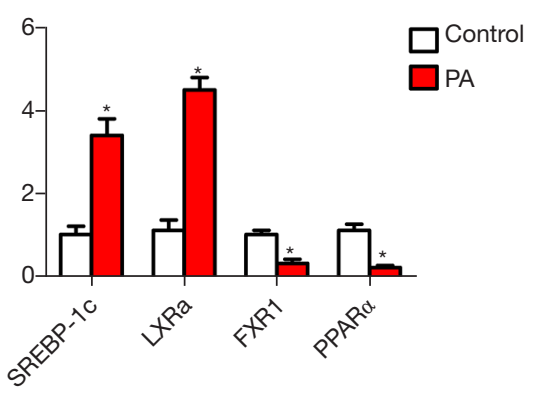

C

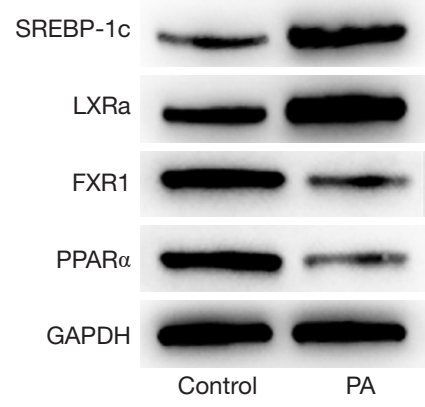

D

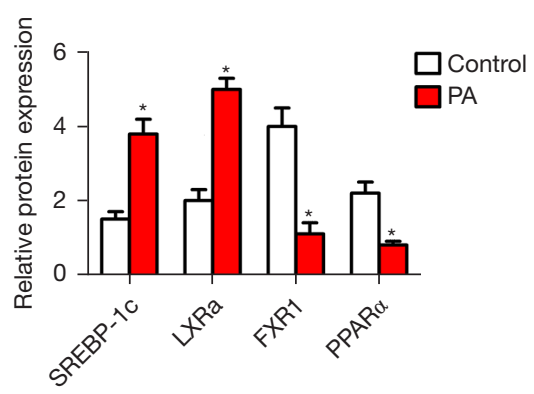

E

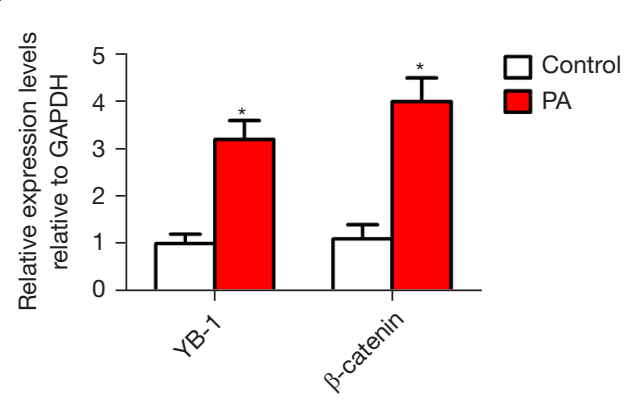

$\mathrm{F}$

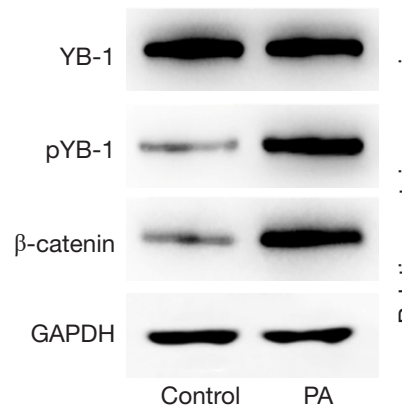

G

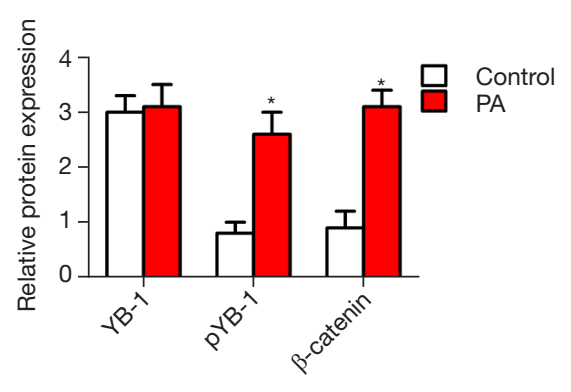

$\mathrm{H}$

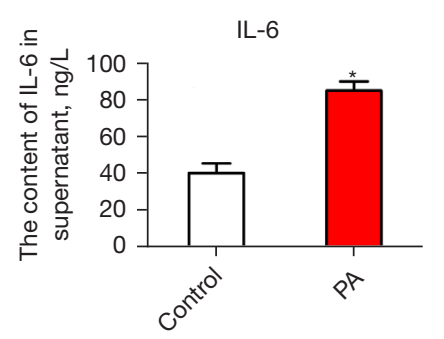

I

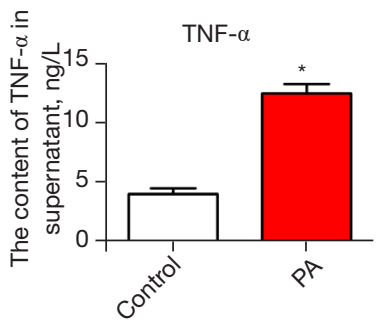

Figure 2 The expression levels of YB-1 and $\beta$-catenin were higher in steatosis LO2 cells in vitro. (A) Oil Red O staining showing lipid deposits (scale bar=100 $\mu \mathrm{m}, \mathrm{n}=3$ per group); (B) qRT-PCR detected the expression levels of the genes related to lipid synthesis (SREBP-1 $c$ and $L X R a$ ) and $\beta$-oxidation (FXR1 and PPAR $\alpha$ ) (*, $\mathrm{P}<0.05$ compared with the control group, $\mathrm{n}=3$ per experiment); (C,D) WB showing the expression levels of SREBP-1c, LXRa, FXR1, and PPAR $\alpha$, and histogram presenting quantification of the immune score for the corresponding proteins in the above groups (*, $\mathrm{P}<0.05$ compared with the control group, $\mathrm{n}=3$ per experiment); (E-G) qRT-PCR and WB assays showing the gene and protein expression levels of $Y B-1$ and $\beta$-catenin (*, $\mathrm{P}<0.05$ compared with the control group, $\mathrm{n}=3$ per experiment); (H,I) ELISA assay measured the contents of TNF $\alpha$ and IL-6 in the supernatants of each group ( ${ }^{*}, \mathrm{P}<0.05$ compared with the control group, $\mathrm{n}=3$ per experiment). $Y B-1, \mathrm{y}$-box binding protein 1; WB, Western blot; qRT-PCR, Quantitative Real-time PCR; ELISA, Enzyme-linked immunosorbent assay; SREBP-1c, sterol regulatory element binding protein-1c; $L X R a$, Liver X Receptor $\alpha ; F X R 1$, farnesoid X receptor1; PPAR $\alpha$, peroxisome proliferator-activated receptor-alpha; TNF $\alpha$, tumor necrosis factor $\alpha$, IL-6, interleukin 6.

downregulated upon downregulation of $Y B-1$ (Figure $4 A$ ). $\mathrm{GO}$ analysis of the upregulated proteins revealed that $Y B-1$ downregulation promoted proteins associated with oxide synthase activity and glucose homeostasis (Figure 4B).
KEGG pathway analysis demonstrated enrichment in the complement and coagulation, ferroptosis, and PI3K-AKT pathways (Figure $4 C$ ). WB confirmed that the downregulation of $Y B-1$ upregulated pGSK-3 $\beta$ and 


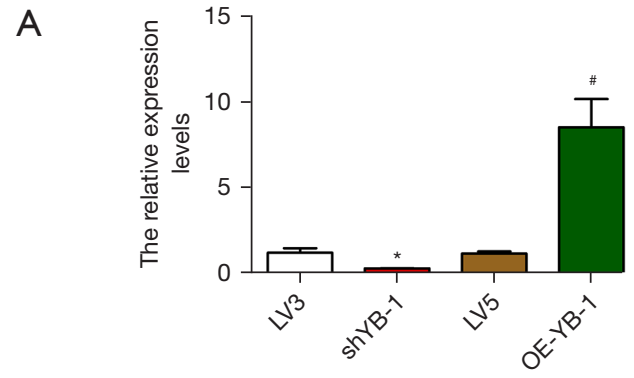

C

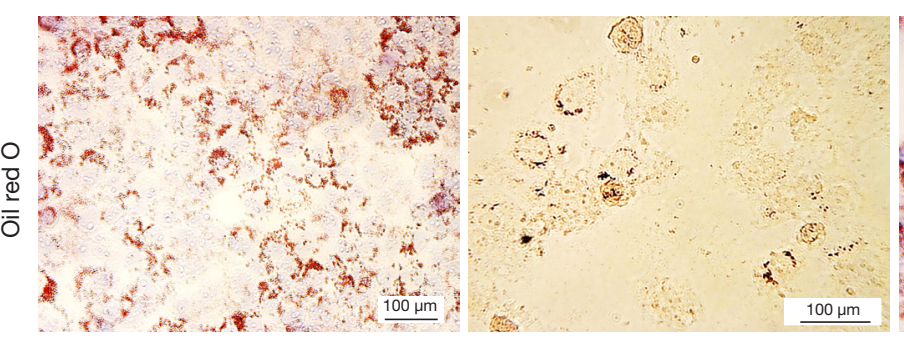

LV3

D
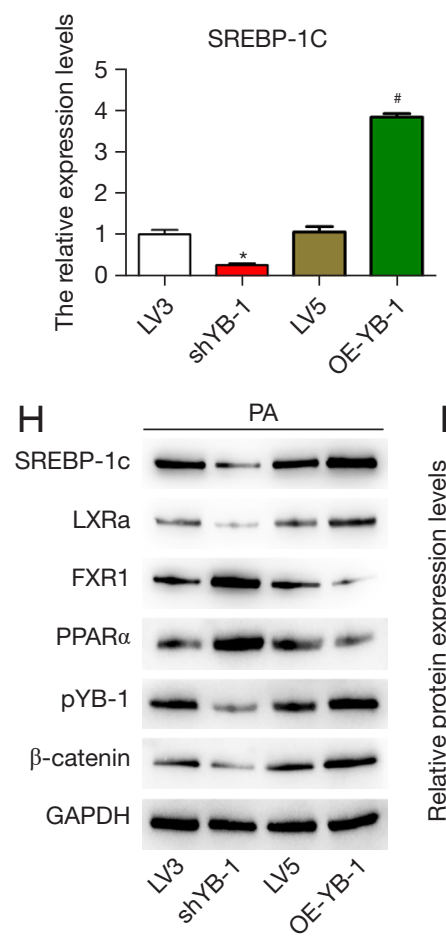

PA
B

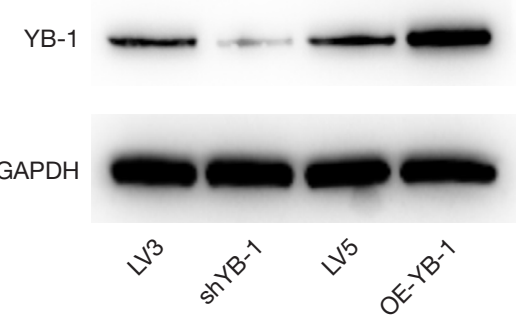

E

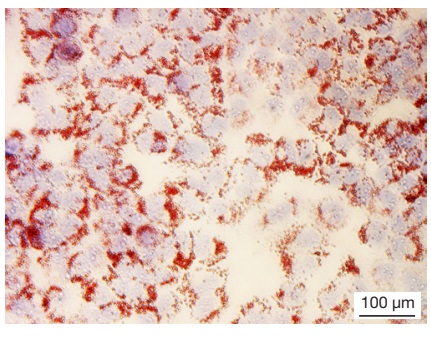

LV5

F

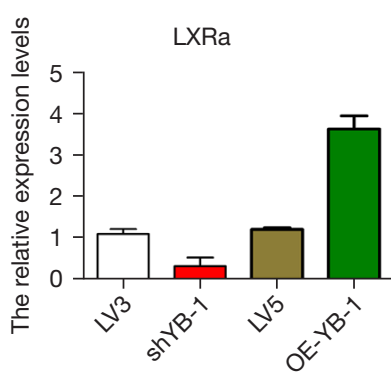

I

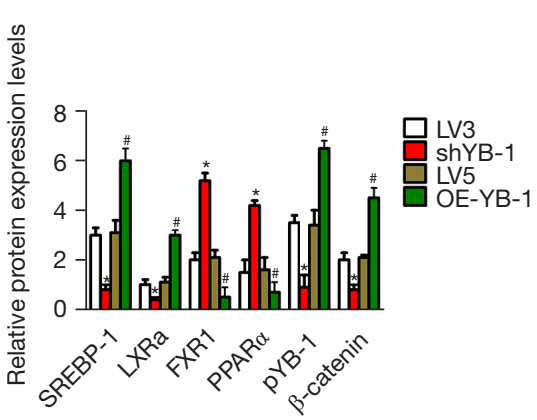

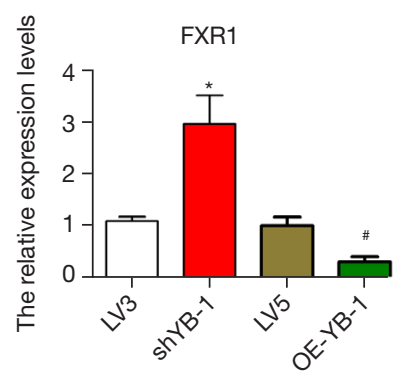

J

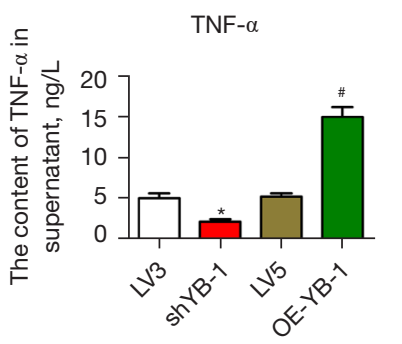

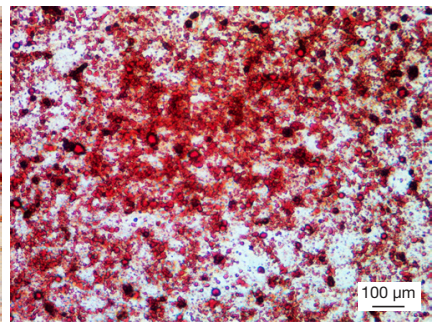

OE-YB-1

G

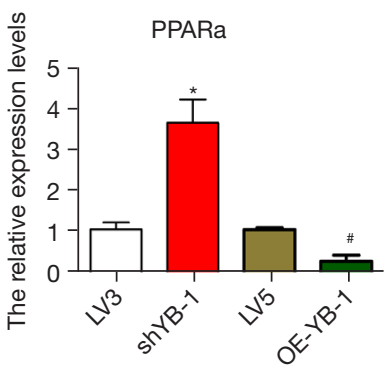

K

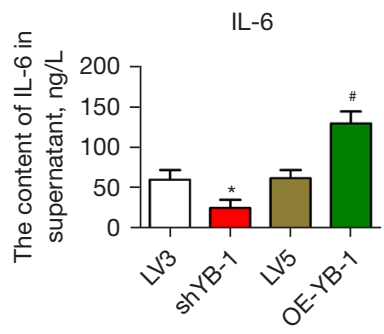

Figure 3 YB-1 could regulate lipid synthesis and the expression of $\beta$-catenin in LO2 cells in vitro. (A,B) The gene and protein expression levels of $Y B-1\left({ }^{*} \mathrm{P}<0.05\right.$ compared with $\mathrm{LV} 3,{ }^{*} \mathrm{P}<0.05$ compared with $\mathrm{LV} 5, \mathrm{n}=3$ per experiment); (C) lipid deposits were detected by Oil Red O staining (scale bar $=100 \mu \mathrm{m}, \mathrm{n}=3$ per group); (D-G) the mRNA expression levels of SREBP-1c, LXRa, FXR1, and PPAR $\alpha$ in each group (*, $\mathrm{P}<0.05$ compared with LV3; " $\mathrm{P}<0.05$ compared with $\mathrm{LV} 5, \mathrm{n}=3$ per experiment); (H,I) the protein expression levels of SREBP-1c, LXRa, FXR1, and PPAR $\alpha$ in each group ${ }^{*}, \mathrm{P}<0.05$ compared with LV3; ${ }^{*}, \mathrm{P}<0.05$ compared with $\mathrm{LV} 5, \mathrm{n}=3$ per experiment); (J,K) ELISA assay measured the contents of TNF $\alpha$ and IL-6 in the supernatants of each group $\left(^{*}, \mathrm{P}<0.05\right.$ compared with LV3; * $\mathrm{P}<0.05$ compared with LV5, n=3 per experiment). $Y B-1$, y-box binding protein 1; SREBP-1c, sterol regulatory element binding protein-1c; LXRa, Liver X Receptor $\alpha$; FXR1, farnesoid X receptor1; $P P A R \alpha$, peroxisome proliferator-activated receptor-alpha; TNF $\alpha$, tumor necrosis factor $\alpha$, IL-6, interleukin 6 . 
A

\begin{tabular}{|c|c|c|c|}
\hline Comparisons & Up- & Down- & All- \\
\hline $\mathrm{KD} / \mathrm{NC}$ & 300 & 376 & 676 \\
\hline
\end{tabular}

B

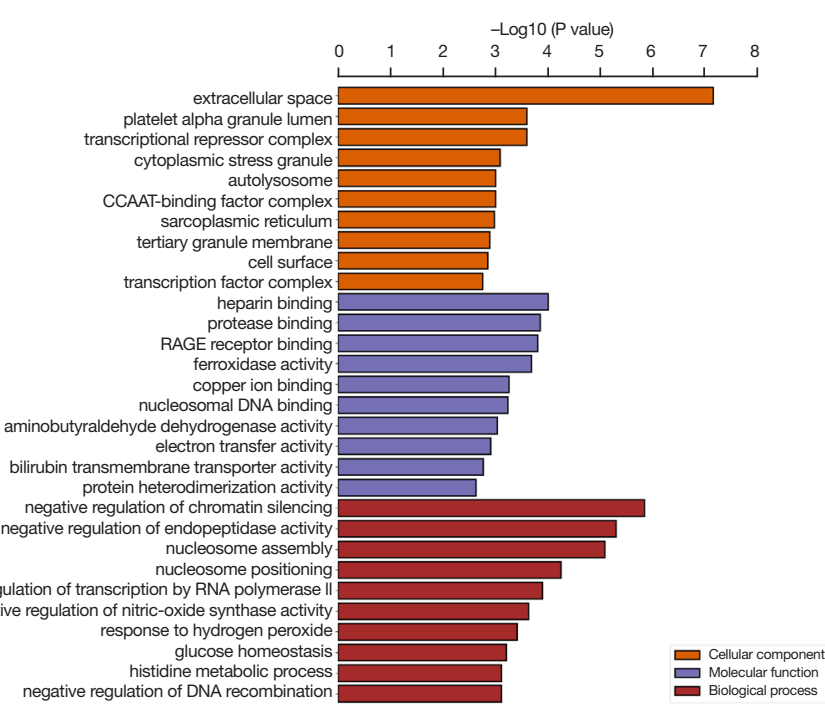

C

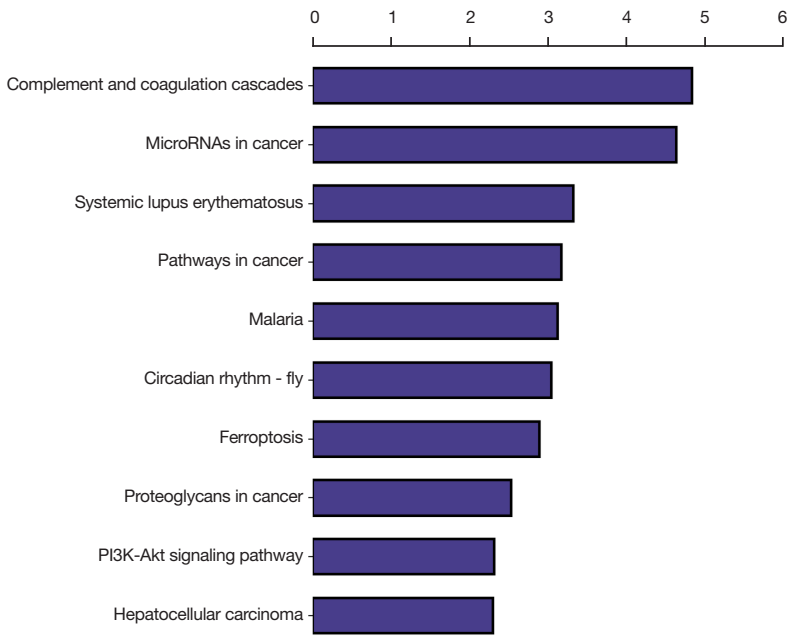

D

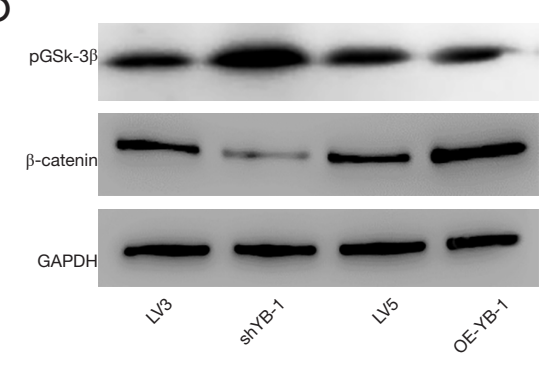

$\mathrm{E}$

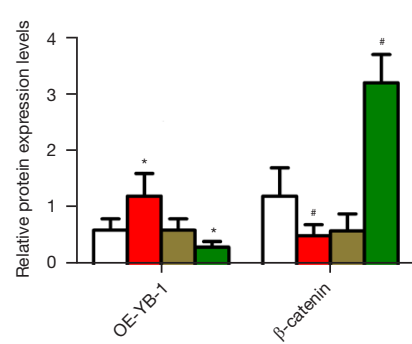

$\mathrm{F}$

吕 $\mathrm{Ln}^{\mathrm{V} 3}$

吕 ${ }^{\mathrm{N} 5}$

吕 OE-YB-1

\section{G}

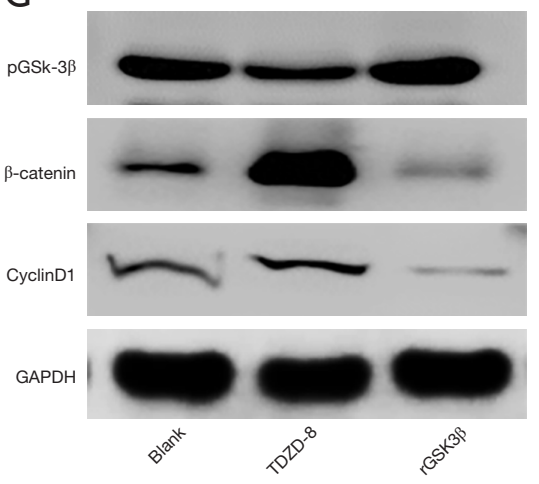

$\mathrm{H}$

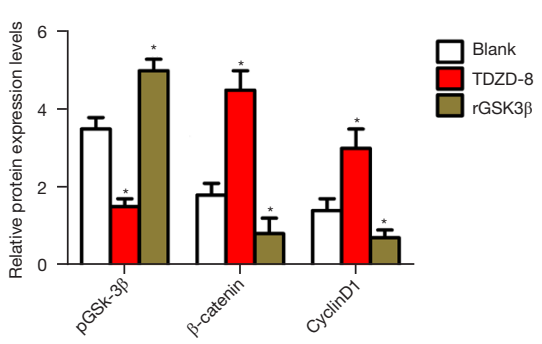

I

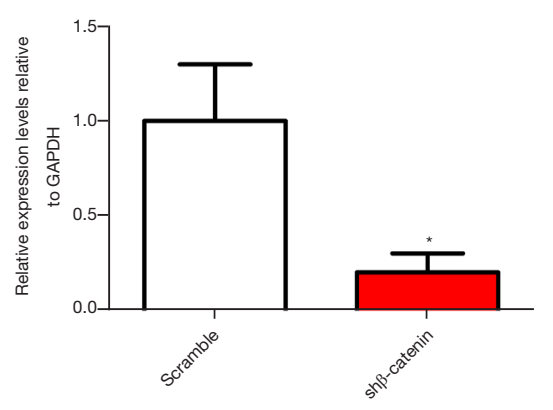




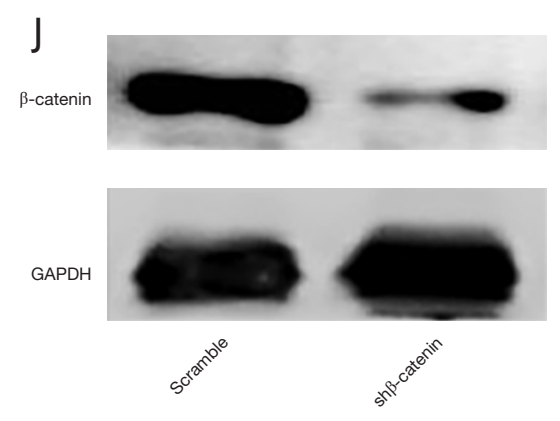

M

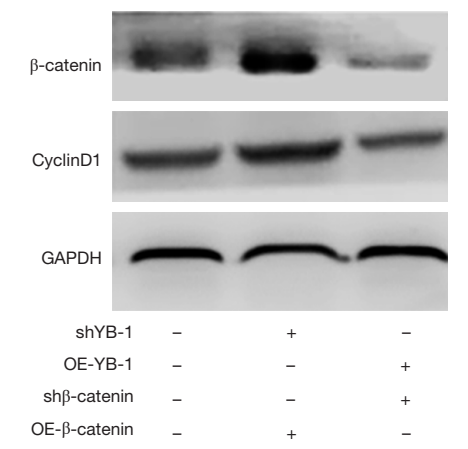

$\mathrm{K}$

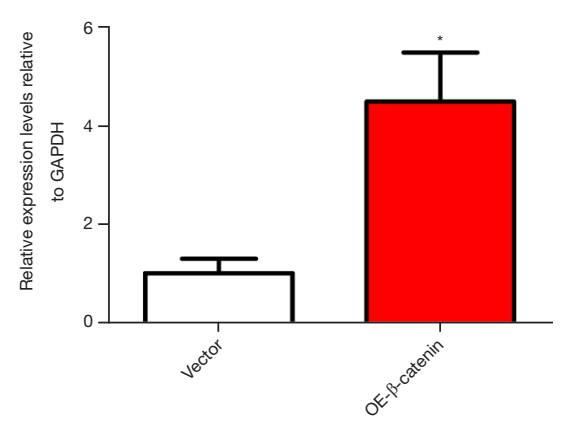

N

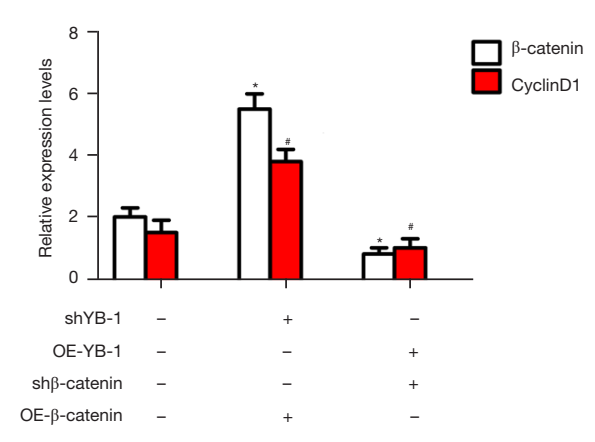

L

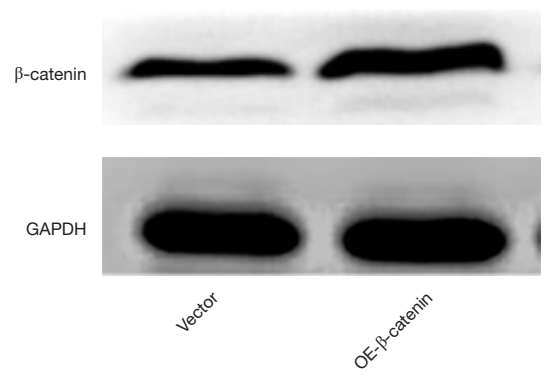

Figure 4 YB-1 combined with pGSK3 $\beta$ regulated the expression of $\beta$-catenin. (A) Protein quantitative results showing the number of upregulated and downregulated proteins (the expression difference was greater than 1.2 times (up and down) and $\mathrm{P}$ value ( $t$-test) was less than 0.05); (B) GO enrichment analysis showing the biological functions of the affected proteins; (C) KEGG pathway enrichment analysis showing significantly affected metabolic and signaling transduction pathways. (D,E) Relative protein expression levels of pGSK3 $\beta$ and $\beta$-catenin were analyzed by WB (* ${ }^{*} \mathrm{P}<0.05$ compared with LV3; *, $\mathrm{P}<0.05$ compared with LV5, n=3 per experiment). (F) LO2 cell lysates were co-precipitated with anti-pGSK3 $\beta$ and anti- $Y B-1$ antibodies and normal IgG as a negative control antibody, and then detected by $Y B-1$ and pGSK3 $\beta$ antibodies, with $20 \%$ of total cell lysates used as input. $(\mathrm{G}, \mathrm{H})$ WB detected the effect of TDZD-8 (GSK3 $\beta$-specific inhibitor) and rGSK3 $\beta$ (recombinant mouse GSK3 $\beta$ protein) on the expression levels of $\beta$-catenin and its target protein CyclinD1 in LO2 cells cultured in DMEM + PA for $72 \mathrm{~h}$. Histogram showing WB quantification ( ${ }^{*}, \mathrm{P}<0.05$ compared with blank, $\mathrm{n}=3$ per experiment). (I,J) RT-PCR and WB demonstrated the effect of shYB-1 on the expression of $Y B-1$ ( $^{*} \mathrm{P}<0.05$ compared with the scramble group, $\mathrm{n}=3$ per experiment). (K,L) RT-PCR and WB demonstrated the effect of $\mathrm{OE}-Y B-1$ on the expression of $Y B-1$ ( $^{*}, \mathrm{P}<0.05$ compared with the scramble group, $\mathrm{n}=3$ per experiment). (M,N) WB showing the expression level of $\beta$-catenin and its target protein CyclinD1 $\left(^{*}, \mathrm{P}<0.05\right.$ compared with groups without any treatment; ${ }^{\#}, \mathrm{P}<0.05$ compared with groups without any treatment, $\mathrm{n}=3$ per experiment). YB-1, y-box binding protein 1; WB, Western blot; qRT-PCR, Quantitative Realtime PCR; GSK3 $\beta$, glycogen synthase kinase 3 beta; pGSK3 $\beta$, phosphorylation glycogen synthase kinase 3 beta; rGSK3 $\beta$; recombinant murine GSK3 $\beta$ protein.

downregulated $\beta$-catenin, but upregulation of $Y B-1$ led to $\mathrm{pGSK}-3 \beta$ downregulation and upregulated $\beta$-catenin (Figure $4 D, 4 E$ ). Subsequently, a Co-IP assay showed that $Y B-1$ complexed pGSK3 $\beta$ (Figure $4 F$ ). Such findings suggest that the $Y B$-1-regulated $W \mathrm{nt} / \beta$-catenin signaling pathway could be orchestrated through pGSK3 $\beta$ degradation. Consequently, the LO2 cell line was exposed to a GSK3 $\beta$ inhibitor (TDZD-8; f.c. $2.5 \mu \mathrm{M}$ ) and activator (recombinant murine GSK3 $\beta$ protein $(\mathrm{rGSK} 3 \beta)$ ) at $90 \mathrm{ng} / \mathrm{mL}$ once daily in DMEM + PA for $72 \mathrm{~h}$. WB demonstrated that TDZD-8 effectively led to pGSK3 $\beta$ downregulation, together with inducing $\beta$-catenin (and its target protein CyclinD1) upregulation. In contrast, rGSK3 $\beta$ demonstrated contrasting influences on the Wnt/ $\beta$-catenin signaling pathway, suggesting that $\beta$-catenin is a downstream target of pGSK3 $\beta$ (Figure $4 G, 4 H$ ). Therefore, we constructed $\operatorname{sh} \beta$-catenin and a corresponding scramble, and $\mathrm{OE}-\beta$-catenin together with empty-vector plasmids. 
Study outcomes indicated that $\operatorname{sh} \beta$-catenin and OE$\beta$-catenin regulate $\beta$-catenin at the transcriptomic and proteomic levels (Figure 4I-4L). Moreover, we confirmed that downregulation of $\beta$-catenin and its target CyclinD1 by $\operatorname{sh} Y B-1$ could be rescued by OE- $\beta$-catenin, and upregulation of $\beta$-catenin and its target CyclinD1 by OE$Y B-1$ could be inhibited by $\operatorname{sh} \beta$-catenin (Figure $4 M, 4 N$ ).

\section{Reverse regulation of $\beta$-catenin reversed the effect of $Y B-1$ on lipid synthesis in LO2 cells}

To further investigate whether the effect of $Y B-1$ on LO2 cell lipid synthesis was realized by regulating $\beta$-catenin, Oil Red O staining was applied to observe lipid synthesis in LO2 cells cultured in DMEM + PA for $72 \mathrm{~h}$. The results showed that downregulation of $Y B-1$ impeded lipid synthesis, although this effect was reversed through $\beta$-catenin overexpression. In addition, upregulation of $Y B-1$ increased lipid synthesis, but this phenomenon could be abolished by downregulation of $\beta$-catenin (Figure $5 A$ ). Then, $\mathrm{WB}$ assays demonstrated that downregulation of $Y B-1$ inhibited the expression levels of $S R E B P-1 c$ and $L X R a$, and increased the expression levels of FXR1 and PPAR $\alpha$. However, this phenomenon could be reversed by overexpression of $\beta$-catenin. Furthermore, the results also indicated that upregulation of $Y B-1$ increased the expression levels of $S R E B P-1 c$ and $L X R a$, and decreased the expression levels of FXR1 and PPAR a, but this phenomenon could also be reversed by downregulation of $\beta$-catenin (Figure $5 B, 5 C$ ). RT-PCR showed that the relative gene expression levels of SREBP-1c, LXRa, FXR1, and PPAR $\alpha$ were consistent with the protein expression levels (Figure 5D). Finally, ELISA assays confirmed that the concentrations of TNF $\alpha$ and IL-6 in the supernatants were consistent with the degree of steatosis in the above groups (Figure 5E, 5 F).

\section{YB-1 regulated lipid synthesis in hepatocytes through orchestrating the Wnt/B-catenin signaling pathway in a mouse model}

The results of the in vivo study indicated that $Y B-1$ was highly expressed in NAFLD livers, but $Y B-1$ expression was effectively inhibited by downregulation of $Y B-1$, and $Y B-1$ expression was higher with upregulation of $Y B-1$ (Figure 6A,6B). In addition, this study also identified $\beta$-catenin upregulation in NAFLD livers, although the expression of $\beta$-catenin was significantly inhibited by downregulation of $Y B-1$, and the expression of $\beta$-catenin was significantly increased by upregulating $\beta$-catenin (Figure 6C,6D). However, reverse regulation of $\beta$-catenin could reverse the effect of $Y B-1$ on the $\beta$-catenin expression (Figure 6E, 6F). Furthermore, Oil Red O staining demonstrated that downregulation of $Y B-1$ inhibited lipid synthesis in NAFLD mouse livers, but upregulation of $Y B-1$ promoted lipid synthesis (Figure $6 G$ ). Interestingly, the effect of $Y B-1$ on lipid synthesis in NAFLD mouse livers could be reversed by reverse regulation of $\beta$-catenin (Figure $6 \mathrm{H}$ ). WB indicated that the inhibited expression of SREBP-1c and $L X R a$ by downregulating $Y B-1$ could be rescued by upregulation of $\beta$-catenin, and the increased expression of FXR1 and PPAR $\alpha$ by downregulating $Y B-1$ could also be inhibited by upregulation of $\beta$-catenin. The increased expression of SREBP-1c and $L X R a$ by upregulating $Y B-1$ could be rescued by downregulation of $\beta$-catenin, and the inhibited expression of FXR1 and $P P A R \alpha$ by upregulating $Y B-1$ could also be increased by downregulation of $\beta$-catenin (Figure 6I,67). Finally, we also confirmed that the expression levels of TNF $\alpha$ and IL- 6 in NAFLD livers were consistent with the degree of steatosis (Figure 6K,6L).

\section{Discussion}

NAFLD is increasing year by year, posing a great burden to human health and society, and affecting $20-30 \%$ of the population worldwide (16). Excessive accumulation of triglycerides in hepatocytes is the hallmark of NAFLD, which is due to the imbalance between lipid deposition and clearance (17). Although investigators have recently reported the molecular mechanisms of NAFLD pathogenesis (18-20), they still require further research. In this study, we first found that the expression levels of $Y B-1$ and $\beta$-catenin were elevated in mouse NAFLD livers. Then, in vitro analysis confirmed that the effect of $Y B-1$ on lipid synthesis and $\beta$-oxidation in $\mathrm{LO} 2$ cells was facilitated by regulating the $\mathrm{Wnt} / \beta$-catenin signaling pathway. Additional analyses identified that $Y B-1$ develops a complex with pGSK3 $\beta$ to regulate the $\mathrm{Wnt} / \beta$-catenin signaling pathway and its target CyclinD1 in steatosis LO2 cells. Finally, we also confirmed that the effect of $Y B-1$ on lipid synthesis and $\beta$-oxidation in mouse NAFLD livers was facilitated by regulating the $\mathrm{Wnt} / \beta$-catenin signaling pathway.

Recent investigations have confirmed that $Y B-1$, as a member of the cold shock protein family, plays a pivotal role in the progression of liver injury and fibrosis, and the initiation and development of hepatic carcinoma (21-23). In 
A

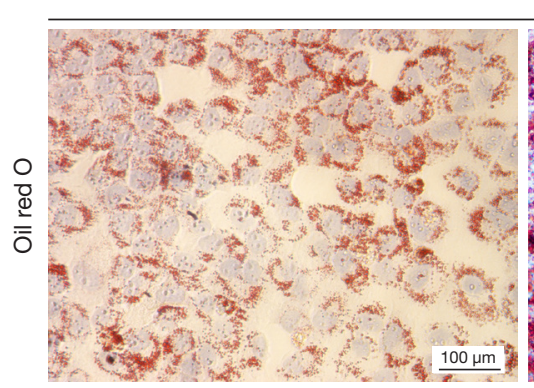

shYB-1

OE-YB-1

$\operatorname{sh} \beta$-catenin

OE- $\beta$-catenin

B

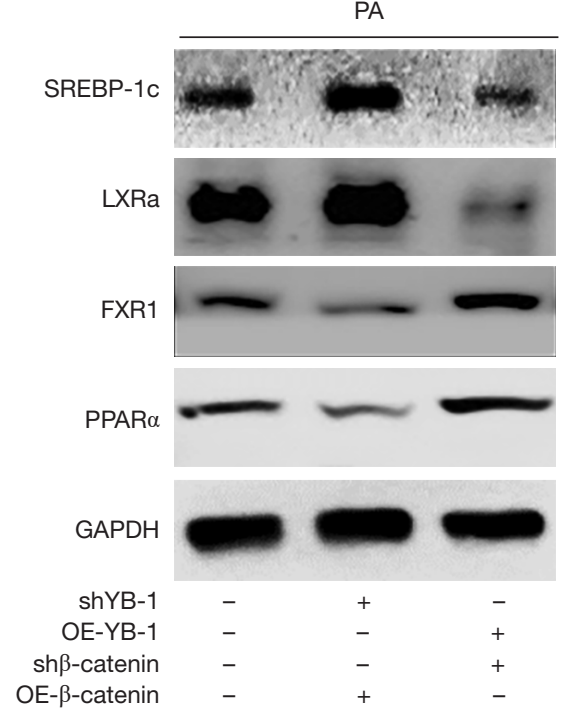

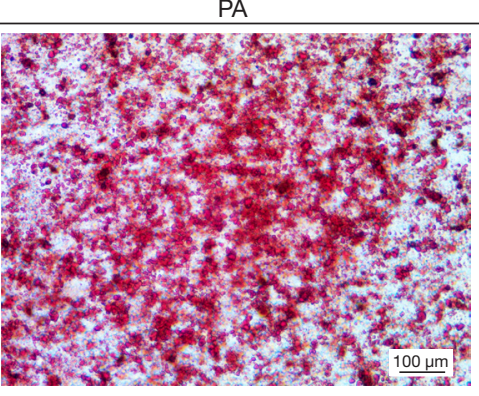

$+$

$-$
C

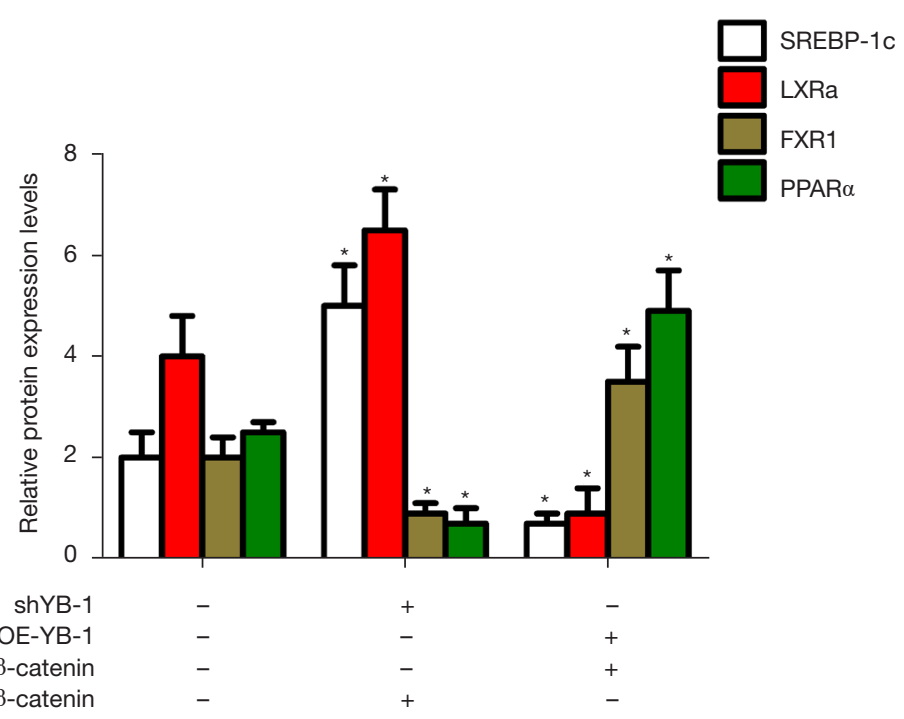

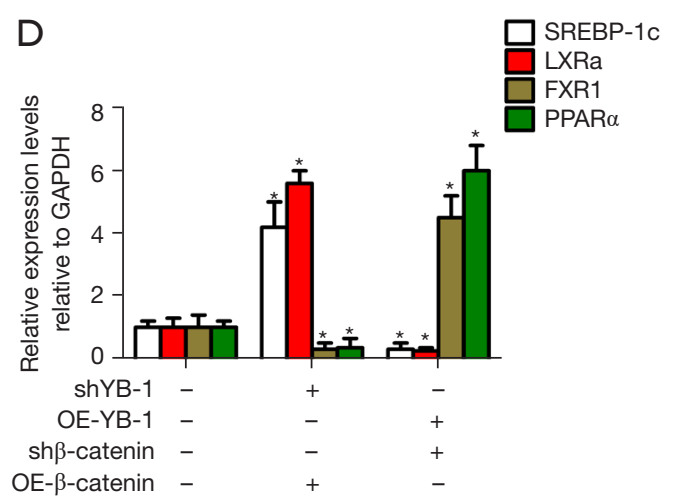

$E$

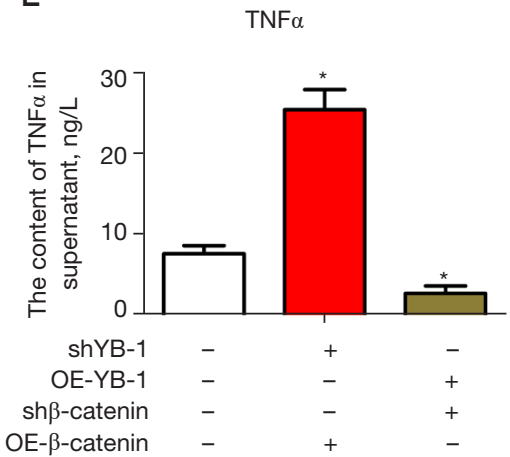

$\mathrm{F}$

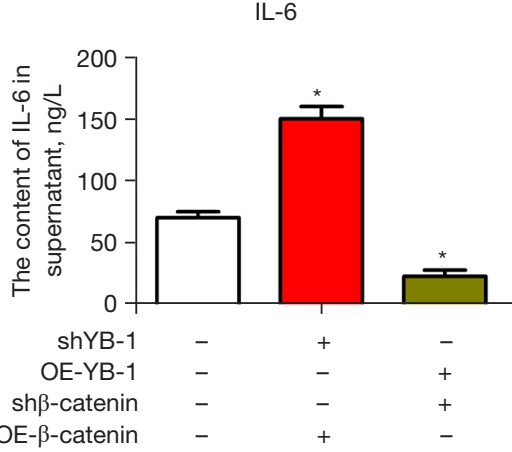

Figure 5 Reverse regulation of $\beta$-catenin reversed the effect of $Y B-1$ on lipid synthesis in LO2 cells. (A) Oil Red O staining showing lipid deposits in each group (scale bar $=100 \mu \mathrm{m}, \mathrm{n}=3$ per group); (B,C) the expression levels of SREBP-1c, LXRa, FXR1, and PPAR $\left({ }^{*}, \mathrm{P}<0.05\right.$ compared with groups without any treatment, $\mathrm{n}=3$ per experiment); (D) RT-PCR indicating the gene expression of $S R E B P-1 c, L X R a, F X R 1$, and PPAR $\alpha{ }^{*}, \mathrm{P}<0.05$ compared with groups without any treatment, $\mathrm{n}=3$ per experiment); (E,F) ELISA assay detected the contents of TNF $\alpha$ and IL-6 in the supernatants of the above groups $\left(^{*}, \mathrm{P}<0.05\right.$ compared with groups without any treatment, $\mathrm{n}=3$ per experiment). $Y B-1$, $\mathrm{y}$-box binding protein 1; qRT-PCR, Quantitative Real-time PCR; ELISA, Enzyme-linked immunosorbent assay; SREBP-1c, sterol regulatory element binding protein-1c; $L X R a$, Liver X Receptor $\alpha$; FXR1, farnesoid X receptor1; PPAR $\alpha$, peroxisome proliferator-activated receptor-alpha; TNF $\alpha$, tumor necrosis factor $\alpha$, IL-6, interleukin 6. 
A

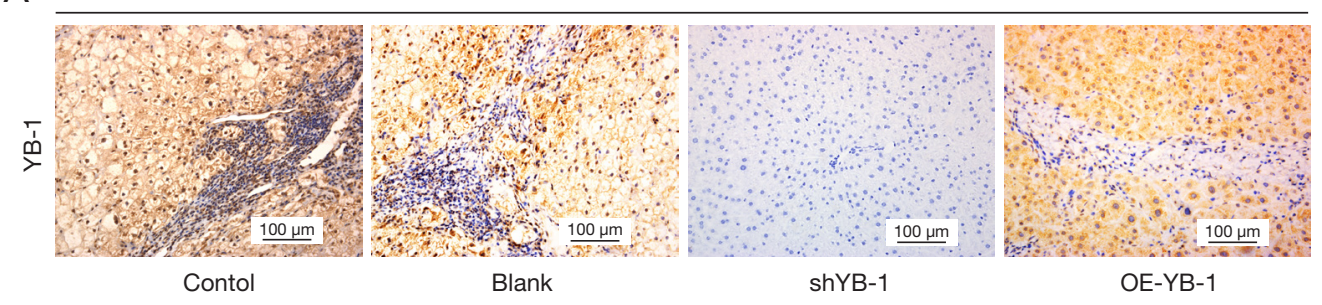

C

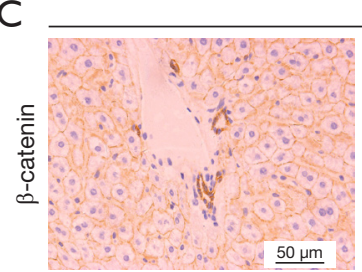

Contol

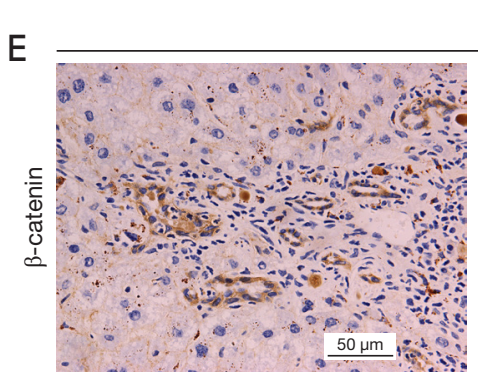

Blank

\section{G}

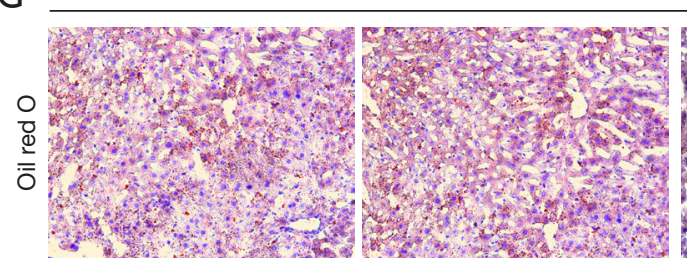

Contol

Blank

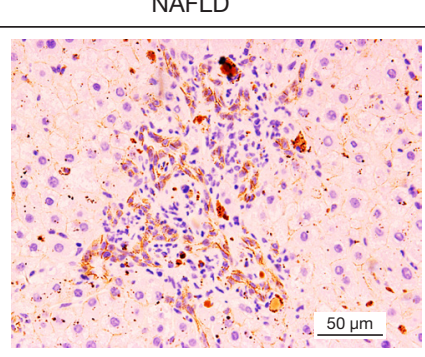

shYB-1+OE- $\beta$-catenin

NAFLD

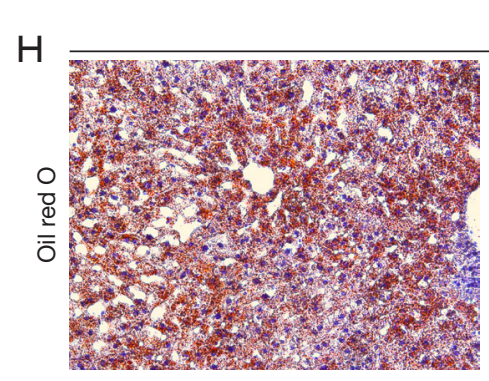

Blank

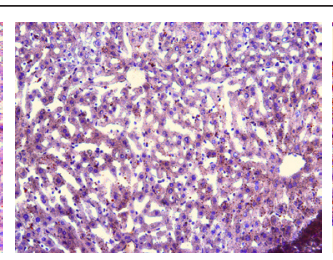

shYB-1

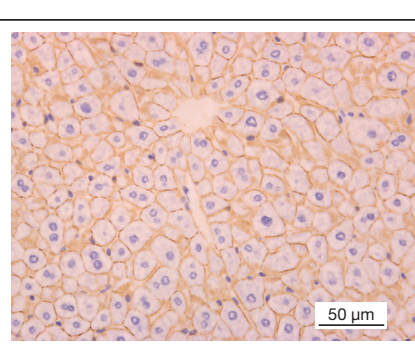

OE-YB- $1+\operatorname{sh} \beta$-catenin

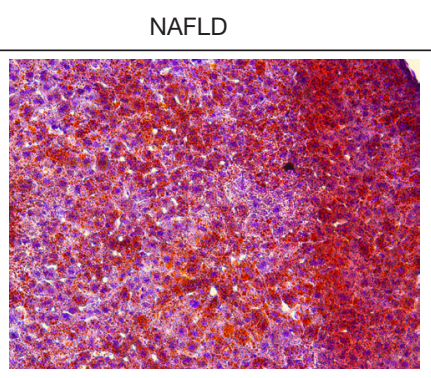

shYB-1+OE- $\beta$-catenin

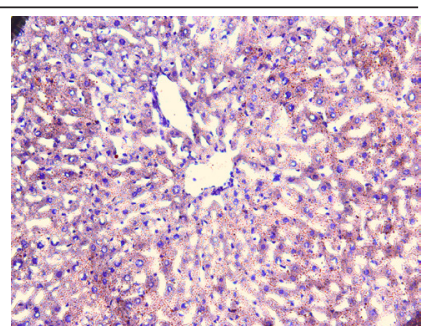

OE-YB-1+sh $\beta$-catenin

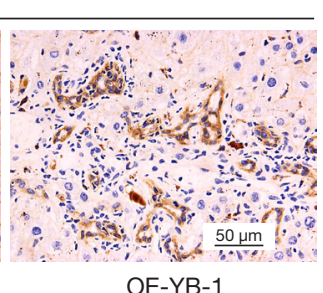

OE-YB-1

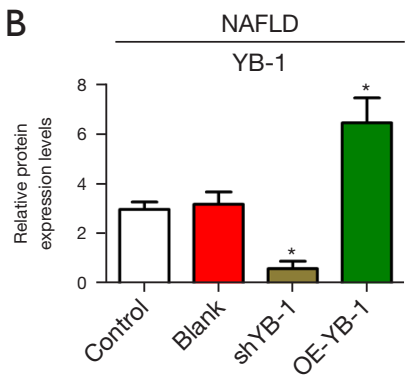

D

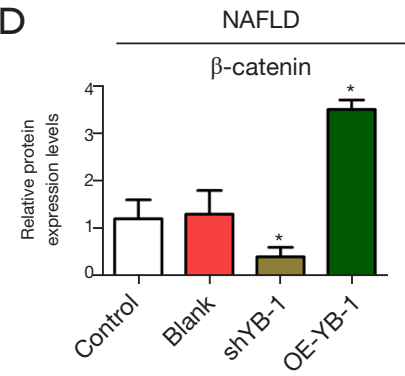

$\mathrm{F}$
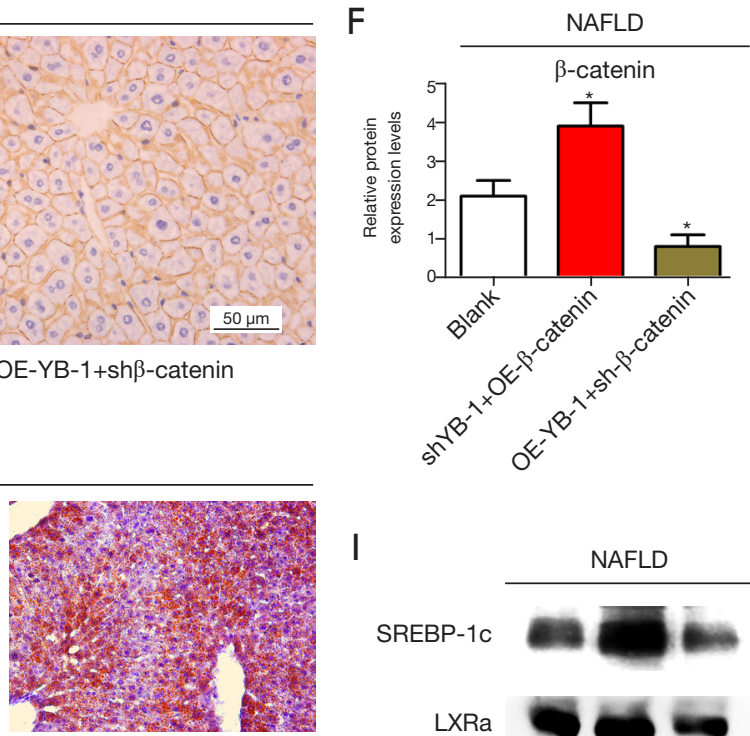

OE-YB-1

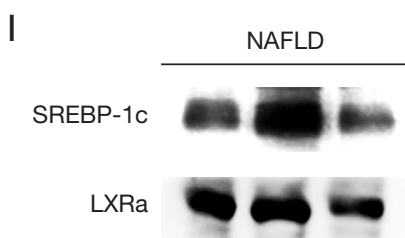

FXR1

PPAR $\alpha$

GAPDH

Blank

shYB-1

OE-YB-1

$\operatorname{sh} \beta$-catenin $\mathrm{OE}-\beta$-catenin 

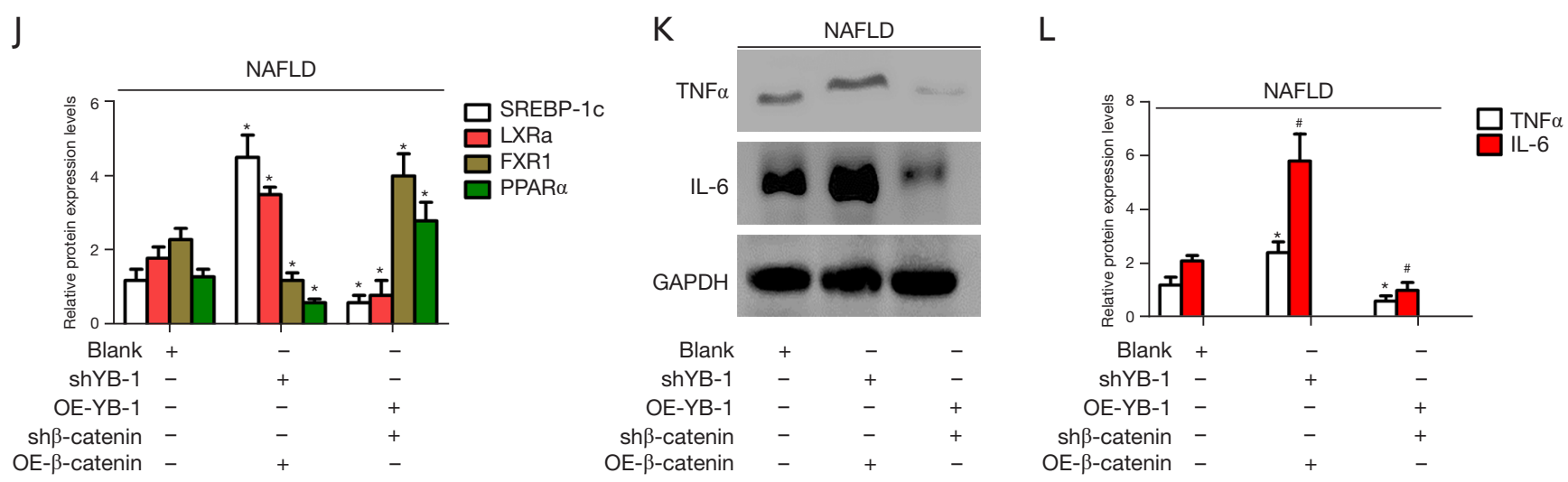

Figure 6 YB-1 regulates lipid synthesis by regulating the Wnt/ $\beta$-catenin signaling pathway in vivo. (A,B) IH and histogram presenting quantification of the immune score for $Y B-1$ in each group (scale bar $=100 \mu \mathrm{m}, \mathrm{n}=20$ per group;, $\mathrm{P}<0.05$ compared with the control and blank group, $\mathrm{n}=3$ per experiment); (C,D) $\mathrm{IH}$ and histogram presenting quantification of the immune score for $\beta$-catenin in each group (scale bar $=50$ $\mu \mathrm{m}, \mathrm{n}=20$ per group; * $\mathrm{P}<0.05$ compared with the control and blank group, $\mathrm{n}=3$ per experiment); (E,F) IH showing the relative expression levels of $\beta$-catenin (scale bar $=50 \mu \mathrm{m}, \mathrm{n}=20$ per group; * $\mathrm{P}<0.05$ compared with the control and blank group, $\mathrm{n}=3$ per experiment); (G,H) Oil Red $\mathrm{O}$ staining showing lipid deposits in each group (scale bar $=50 \mu \mathrm{m}, \mathrm{n}=20$ per group); $(\mathrm{I}, \mathrm{J}) \mathrm{WB}$ indicating the relative expression levels of $S R E B P-1 c$, $L X R a, F X R 1$, and PPAR $\alpha$ in each group ( ${ }^{*}, \mathrm{P}<0.05$ compared with groups without any treatment, $\mathrm{n}=3$ per experiment). (K,L) WB showing the relative expression levels of TNF $\alpha$ and IL-6 in each group $\left(^{*}, \mathrm{P}<0.05\right.$ compared with groups without any treatment; ${ }^{*}$, $\mathrm{P}<0.05$ compared with groups without any treatment $\mathrm{n}=3$ per experiment). $Y B-1$, y-box binding protein 1 ; IH; Immunohistochemistry; WB, Western blot; SREBP$1 c$, sterol regulatory element binding protein-1c; $L X R a$, Liver X Receptor $\alpha ; F X R 1$, farnesoid X receptor1; PPAR $\alpha$, peroxisome proliferatoractivated receptor-alpha; TNF $\alpha$, tumor necrosis factor $\alpha, \mathrm{IL}-6$, interleukin 6.

our previous study, we found that YB-1 regulated Collagen I secretion in hepatic progenitor cells via PDGFR- $\beta$ / ERK/p90RSK Signalling, and influenced the progression of liver fibrogenesis (24). Liu and colleagues found that $t$ YB-1 augments sorafenib resistance through the PI3K/Akt signaling pathway in HepG2, a human hepatocarcinoma cell line (25). Wang and colleagues demonstrated that in acute liver injury model in C57BL/6J mouse induced by Lipopolysaccharide/D-galactosamine, phosphorylation YB-1 inhibition could downregulate the expression of Nlrp3 inflammasome, and protecting acute liver injury (23). Interestingly, McCauley et al. found that $Y B-1$ participated in fatty acid synthesis in clear cell renal carcinoma (10). However, up to now, there have been few studies on the effects of $Y B-1$ on lipid metabolism in hepatocytes. This investigation demonstrated $Y B-1$ upregulation in mouse NAFLD livers and steatosis LO2 cells induced by PA.

To investigate the correlation between the expression level of $Y B-1$ and lipid metabolism, we established an LO2 cell NAFLD model in vitro, and confirmed that $Y B-1$ was highly activated in the progression of $\mathrm{LO} 2$ cell lipid synthesis. Meanwhile, fat synthetases $S R E B P-1 c$ and $L X R a$ were also highly activated, while $\beta$-oxidation-related enzymes FXR1 and PPAR $\alpha$ were inhibited. We also found that the concentrations of inflammatory cytokines TNF $\alpha$ and IL-6 were higher in the supernatants of the steatosis LO2 cell group. Follow-up investigations revealed that inhibiting $Y B-1$ through $Y B-1$ gene silencing decreased lipid synthesis and the expression levels of $S R E B P-1 c$ and $L X R a$, but increased the expression levels of FXR1 and PPAR $\alpha$. However, $Y B-1$ upregulation by $Y B-1$ gene overexpression increased lipid synthesis and the expression levels of SREBP$1 c$ and $L X R a$, but decreased the expression levels of FXR1 and PPAR $\alpha$. Finally, we also found that the concentrations of TNF $\alpha$ and IL-6 were lower in the supernatants of LO2 cells transfected with a lentivirus of $Y B-1$ gene silencing, but the concentrations of TNF $\alpha$ and IL- 6 were higher in the supernatants of $\mathrm{LO} 2$ cells transfected with a lentivirus of $Y B-1$ overexpression. These data indicated that $Y B-1$ could participate in LO2 cell lipid metabolism.

GSK3 $\beta$ is a main protein of the multi-protein destruction complex. In unstimulated cells, the ubiquitin proteases after phosphorylation by GSK3 $\beta$ were shown to degrade $\beta$-catenin, which resulted in $\beta$-catenin not being able to translocate to the cell nucleus, and the $\mathrm{Wnt} / \beta$-catenin signaling pathway was inactivated. In unstimulated cells, 
non-phosphorylated cytoplasmic $\beta$-catenin translocated/ accumulated within the nucleus to enable downstream gene regulatory activity $(26,27)$. Recently, a series of investigations indicated that the activation of the $\mathrm{Wnt} / \beta$-catenin signaling pathway contributes to liver injury induced by alcohol consumption (13), and its downregulation increased the levels of proteins involved in glucose aerobic metabolism and $\beta$-oxidation in a mouse swimming training model (28). The above data demonstrate that the $\mathrm{Wnt} / \beta$-catenin signaling pathway plays an important role in inflammation and metabolism, though the involvement of $\mathrm{Wnt} / \beta$-catenin signaling in lipid metabolism and the inflammatory response of the liver remains uncertain. This investigation confirmed that enhanced triggering of $\mathrm{Wnt} / \beta$-catenin took place in the process of liver and LO2 cell steatosis in vivo and in vitro, and that inhibiting the expression of $Y B-1$ by downregulating the $Y B-1$ gene suppressed the activation of this pathway and then decreased lipid synthesis and inflammatory responses. These findings were reversed through $\beta$-catenin overexpression. Next, we confirmed that promoting the expression of $Y B-1$ by upregulating $Y B-1$ gene expression increased the activation of this pathway and then increased lipid synthesis and inflammatory responses. However, this phenomenon was reversed by inhibition of $\beta$-catenin.

These results were similar to previous studies which indicated that the accumulation of $\beta$-catenin in the nucleus promoted lipogenesis in fish, and pGSK3 $\beta$, a phosphorylated form of GSK3 $\beta$, could form a destruction complex with other proteins to regulate $\mathrm{Wnt} / \beta$-catenin triggering $(29,30)$. In addition, this investigation also revealed that the inhibition of pGSK $3 \beta$ could activate the $\mathrm{Wnt} / \beta$-catenin signaling pathway, but that increased pGSK3 $\beta$ suppressed the activation of this pathway, similar to the findings of previous studies (31-33). Recently, some investigations found that $Y B-1$ could form protein complexes with other proteins to perform a series of physiological functions $(34,35)$. In this study, we also found that $Y B-1$ could form a complex with pGSK3 $\beta$ to regulate the $\mathrm{Wnt} / \beta$-catenin signaling pathway. Although this investigation of the molecular mechanisms underlying liver lipid metabolism and inflammatory responses did not bring about extensive evidence, such results can certainly provide further insights into the mechanisms of liver lipid metabolism.

\section{Acknowledgments}

Funding: This study was supported by the Key Project of
Natural Science Research of Universities of Anhui Province, Grant/Award Number: KJ2019A0369.

\section{Footnote}

Reporting Checklist: The authors have completed the ARRIVE reporting checklist. Available at https://dx.doi. org/10.21037/atm-21-5767

Data Sharing Statement: Available at https://dx.doi. org/10.21037/atm-21-5767

Conflicts of Interest: All authors have completed the ICMJE uniform disclosure form (available at https://dx.doi. org/10.21037/atm-21-5767). The authors have no conflicts of interest to declare.

Ethical Statement: The authors are accountable for all aspects of the work in ensuring that questions related to the accuracy or integrity of any part of the work are appropriately investigated and resolved. All the animal procedures were performed in accordance with the Guidelines for the Care and Use of Laboratory Animals of Bengbu Medical College and were approved by the Animal Ethics Committee of Bengbu Medical College (Bengbu, China) under a project license (No. 2021-096).

Open Access Statement: This is an Open Access article distributed in accordance with the Creative Commons Attribution-NonCommercial-NoDerivs 4.0 International License (CC BY-NC-ND 4.0), which permits the noncommercial replication and distribution of the article with the strict proviso that no changes or edits are made and the original work is properly cited (including links to both the formal publication through the relevant DOI and the license). See: https://creativecommons.org/licenses/by-nc-nd/4.0/.

\section{References}

1. Chalasani N, Younossi Z, Lavine JE, et al. The diagnosis and management of nonalcoholic fatty liver disease:

Practice guidance from the American Association for the Study of Liver Diseases. Hepatology 2018;67:328-57.

2. European Association for the Study of the Liver (EASL); European Association for the Study of Diabetes (EASD); European Association for the Study of Obesity (EASO). EASL-EASD-EASO Clinical Practice Guidelines for the management of non-alcoholic fatty liver disease. J Hepatol 
2016;64:1388-402.

3. Berardo C, Di Pasqua LG, Cagna M, et al. Nonalcoholic Fatty Liver Disease and Non-Alcoholic Steatohepatitis: Current Issues and Future Perspectives in Preclinical and Clinical Research. Int J Mol Sci 2020;21:9646.

4. Kucukoglu O, Sowa JP, Mazzolini GD, et al. Hepatokines and adipokines in NASH-related hepatocellular carcinoma. J Hepatol 2021;74:442-57.

5. Ji D, Qin E, Xu J, et al. Non-alcoholic fatty liver diseases in patients with COVID-19: A retrospective study. J Hepatol 2020;73:451-3.

6. Liu XL, Pan Q, Cao HX, et al. Lipotoxic HepatocyteDerived Exosomal MicroRNA 192-5p Activates Macrophages Through Rictor/Akt/Forkhead Box Transcription Factor O1 Signaling in Nonalcoholic Fatty Liver Disease. Hepatology 2020;72:454-69.

7. Sarkar M, Grab J, Dodge JL, et al. Non-alcoholic fatty liver disease in pregnancy is associated with adverse maternal and perinatal outcomes. J Hepatol 2020;73:516-22.

8. Lyabin DN, Eliseeva IA, Ovchinnikov LP. YB-1 protein: functions and regulation. Wiley Interdiscip Rev RNA 2014;5:95-110.

9. Kretov DA, Mordovkina DA, Eliseeva IA, et al. Inhibition of Transcription Induces Phosphorylation of YB-1 at Ser102 and Its Accumulation in the Nucleus. Cells 2019;9:104.

10. McCauley C, Anang V, Cole B, et al. Potential Links between YB-1 and Fatty Acid Synthesis in Clear Cell Renal Carcinoma. Med Res Arch 2020.

11. Weiskirchen R. Commentary on "Re-regulation of hepatic stellate cell contraction and cirrhotic portal hypertension by Wnt/ $\beta$-catenin signaling via interaction with Gli1". Br J Pharmacol 2021;178:378-80.

12. Zhang R, Kikuchi AT, Nakao T, et al. Elimination of Wnt Secretion From Stellate Cells Is Dispensable for Zonation and Development of Liver Fibrosis Following Hepatobiliary Injury. Gene Expr 2019;19:121-36.

13. Xu Y, Chen D, Lin XX, et al. The LRP6 functional mutation rs2302685 contributes to individual susceptibility to alcoholic liver injury related to the $\mathrm{Wnt} / \beta$-cateninTCF1-CYP2E1 signaling pathway. Arch Toxicol 2019;93:1679-95.

14. El-Derany MO, El-Demerdash E. Pyrvinium pamoate attenuates non-alcoholic steatohepatitis: Insight on hedgehog/Gli and Wnt/ $\beta$-catenin signaling crosstalk. Biochem Pharmacol 2020;177:113942.

15. Hatano M, Ojima H, Masugi Y, et al. Steatotic and nonsteatotic scirrhous hepatocellular carcinomas reveal distinct clinicopathological features. Hum Pathol 2019;86:222-32.

16. Estes C, Anstee QM, Arias-Loste MT, et al. Modeling NAFLD disease burden in China, France, Germany, Italy, Japan, Spain, United Kingdom, and United States for the period 2016-2030. J Hepatol 2018;69:896-904.

17. Eslam M, Valenti L, Romeo S. Genetics and epigenetics of NAFLD and NASH: Clinical impact. J Hepatol 2018;68:268-79.

18. Song J, Liu Y, Wan J, et al. SIMPLE is an endosomal regulator that protects against non-alcoholic fatty liver disease by targeting the lysosomal degradation of EGFR. Hepatology 2021. [Epub ahead of print].

19. Tanwar S, Srivastava A, Rosenberg W. Errors in modeling misrepresent the utility of the enhanced liver fibrosis test in the management of non-alcoholic fatty liver disease. J Hepatol 2020;73:1580-1.

20. Zhao Q, Liu J, Deng H, et al. Targeting MitochondriaLocated circRNA SCAR Alleviates NASH via Reducing mROS Output. Cell 2020;183:76-93.e22.

21. Li D, Liu X, Zhou J, et al. Long noncoding RNA HULC modulates the phosphorylation of YB-1 through serving as a scaffold of extracellular signal-regulated kinase and YB-1 to enhance hepatocarcinogenesis. Hepatology 2017;65:1612-27.

22. Xiong $\mathrm{P}$, Zhang J, Xu D, et al. Positive feedback loop of YB-1 interacting with Smad2 promotes liver fibrosis. Biochem Biophys Res Commun 2017;484:753-61.

23. Wang F, Gong S, Wang T, et al. Soyasaponin II protects against acute liver failure through diminishing YB-1 phosphorylation and Nlrp3-inflammasome priming in mice. Theranostics 2020;10:2714-26.

24. Li F, Ma Z, Liu H, et al. Y-box Protein-1 Regulates the Expression of Collagen I in Hepatic Progenitor Cells via PDGFR- $\beta / E R K / p 90 R S K$ Signalling. Stem Cells Int 2017;2017:6193106.

25. Liu T, Xie XL, Zhou X, et al. Y-box binding protein 1 augments sorafenib resistance via the PI3K/Akt signaling pathway in hepatocellular carcinoma. World J Gastroenterol 2021;27:4667-86.

26. Koch S. Regulation of Wnt Signaling by FOX Transcription Factors in Cancer. Cancers (Basel) 2021;13:3446.

27. Steinhart Z, Angers S. Wnt signaling in development and tissue homeostasis. Development 2018;145: dev146589.

28. Balatskyi VV, Palchevska OL, Bortnichuk L, et al. $\beta$-Catenin Regulates Cardiac Energy Metabolism in 
Sedentary and Trained Mice. Life (Basel) 2020;10:357.

29. Xu YC, Xu YH, Zhao T, et al. Waterborne Cu exposure increased lipid deposition and lipogenesis by affecting $\mathrm{Wnt} / \beta$-catenin pathway and the $\beta$-catenin acetylation levels of grass carp Ctenopharyngodon idella. Environ Pollut 2020;263:114420.

30. Kuncewitch M, Yang WL, Molmenti E, et al. Wnt agonist attenuates liver injury and improves survival after hepatic ischemia/reperfusion. Shock 2013;39:3-10.

31. Wang D, Lu G, Shao Y, et al. MiR-182 promotes prostate cancer progression through activating $\mathrm{Wnt} / \beta$-catenin signal pathway. Biomed Pharmacother 2018;99:334-9.

32. Sun YC. Examination of effects of GSK3beta phosphorylation, beta-catenin phosphorylation, and beta- catenin degradation on kinetics of Wnt signaling pathway using computational method. Theor Biol Med Model 2009;6:13.

33. Martin E, Agazie YM. SHP2 Potentiates the Oncogenic Activity of $\beta$-Catenin to Promote Triple-Negative Breast Cancer. Mol Cancer Res 2021. [Epub ahead of print].

34. Liu J, Qu L, Wan C, et al. A novel $\beta 2-\mathrm{AR} / \mathrm{YB}-1 / \beta$-catenin axis mediates chronic stress-associated metastasis in hepatocellular carcinoma. Oncogenesis 2020;9:84.

35. Yang F, Chen S, He S, et al. YB-1 interplays with ER $\alpha$ to regulate the stemness and differentiation of ER-positive breast cancer stem cells. Theranostics 2020;10:3816-32.

(English Language Editor: C. Betlzar)
Cite this article as: Ma Z, Zhu Y, Wang Q, Deng M, Wang J, Li D, Gu L, Zhao R, Yan S. Y-box binding protein 1 regulates liver lipid metabolism by regulating the $\mathrm{Wnt} / \beta$-catenin signaling pathway. Ann Transl Med 2021;9(22):1693. doi: 10.21037/atm-21-5767 